\title{
Total Factor Productivity and Labor Reallocation: the Case of the Korean 1997 Crisis
}

\author{
David M. Benjamin* \\ University of Southampton
}

\author{
Felipe Meza ${ }^{\dagger}$ \\ Universidad Carlos III de Madrid
}

January 31st, 2007

\begin{abstract}
Detrended Total Factor Productivity (TFP), net of changes in capital utilization, fell by 3.3\% after the Korean 1997 financial crisis. Detrended real GDP per working age person fell by $11.9 \%$. We construct a two-sector small open economy model that can account for $30.0 \%$ of the fall in TFP in response to a sudden stop of capital inflows and an increase in international interest rates. Empirically, the fall in TFP follows a reallocation of labor from the more productive manufacturing sector to the less productive agriculture and public sectors. The model has a consumption sector and an investment sector. The reallocation of labor in the data corresponds to a movement from the investment sector to the consumption sector in the model. In the model, a sudden stop raises the costs of imports, which are used more heavily as an input in the investment sector. Also investment falls sharply in response to the increase in international interest rates. We show further that a fall in export demand and working capital requirements can both amplify the effects of the sudden stop. The model accounts for $41.0 \%$ of the fall in GDP.
\end{abstract}

Keywords: Small open economy; Total factor productivity; Korean 1997 crisis; Sudden stop JEL codes: F32; F41

${ }^{*}$ David M. Benjamin: Division of Economics, School of Social Sciences, Highfield Campus, University of Southampton SO17 1BJ, United Kingdom, +44 2380594005 (phone), D . Ben jamin@ soton . ac . uk .

${ }^{\dagger}$ Felipe Meza: Universidad Carlos III de Madrid, Calle Madrid 126, Getafe, Madrid 28903, Spain, +34 91624 5734 (phone), +34 916249875 (fax), fmeza@eco . uc3m. es. Felipe Meza thanks the Ministerio de Educación y Ciencia de España for financial support through project SEJ2004-00968. We thank seminar participants at Universidad Carlos III de Madrid, University of Southampton, Federal Reserve Bank of Minneapolis, University of North Carolina at Chapel Hill, and Econometric Society North American Meetings Chicago 2007, for valuable comments at different stages of this project. In particular, we thank Ákos Valentinyi and Kim J. Ruhl. 


\section{Introduction}

In the aftermath of the economic crisis in Korea in 1997, detrended total factor productivity (TFP), net of changes in capital utilization, fell by $3.3 \%$ percent. Detrended real GDP per capita fell by $11.9 \%$. The fall in TFP is the second largest since $1970 .{ }^{1}$ Large and atypical falls in TFP are common in recent episodes of financial crises, including Mexico, Argentina, and Southeast Asia. We offer both a novel mechanism and a quantitative accounting for a significant fraction of the fall of TFP in Korea between 1997 and $1998 .^{2}$

We present two complementary sets of results. First, we have empirical results driven from a multi-sector model of production. For this set of results we ask a basic question: Did TFP fall because it fell at the sectoral level or did it fall because resources moved from high into low productivity sectors? To answer this question, we decompose changes in TFP as originating in one of two sources: changes in productivity within individual sectors and movements of resources between sectors with different levels of productivity.

We show that the fall in productivity after the crisis is primarily due to the second channel. In relative terms, labor leaves the manufacturing sector for a group of less productive sectors, particulary agriculture and a broad sector that includes public administration, health and education. Manufacturing is approximately twice as productive as these sectors.

For our second set of results, we contribute a small open economy model that quantitatively accounts for much of these resource movements and the fall in TFP. The mechanism has two parts. One part of this mechanism is an increase in the price of imported intermediate inputs which are used most heavily in manufacturing. The second part is the fall in investment in response to international interest rates and the sudden stop of capital inflows. Both forces shift resources away from manufacturing. We generate these effects endogenously within a small open economy model that experiences a sudden stop.

The model has two sectors. Instead of a tradable and a non-tradable sector, the model has a consumption sector and an investment sector. The investment sector produces a good that can be used for consumption, investment and exporting. The consumption sector produces a good that can only be used for consumption. We also assume that the investment sector uses three inputs: capital, labor and materials. Materials are produced using imported intermediate goods as inputs.

The empirical counterpart of the consumption sector is the agricultural plus services sec-

\footnotetext{
${ }^{1}$ The largest fall in TFP was in 1980 after a coup in October 1979. That fall is $7.9 \%$.

${ }^{2}$ We are detrending TFP and GDP by their average geometric growth rates between 1970 and 1997 . In the following sections we discuss our procedure to measure TFP.
} 
tors. The empirical counterpart of the investment sector is the manufacturing plus construction sectors.

The divide between consumption and investment has the following features: First, it splits the sectors in the Korean economy into a high productivity sector where labor fell relatively after the crisis and a low productivity sector in which it grew. In relative terms, labor fell in both the construction and manufacturing sectors and increased in the agriculture and in many of the service sectors. Second, this divide highlights the asymmetric role of imports in production between these sectors. Manufacturing requires a greater amount of imported intermediate goods than any of the consumption sectors, particularly agriculture.

The benchmark experiment is a sudden stop of capital inflows together with an increase in international interest rates. The sudden stop of capital inflows requires the economy to switch from negative to positive net exports. The economy faces a downward sloping demand curve for its exports. As the economy is forced to increase exports, their price, relative to the price of intermediate imported goods, falls. Higher priced imports have a negative impact on the investment sector, reducing the amount of labor it uses. At the same time, the increase in international interest rates leads to a smaller demand for investment goods. Consequently, the overall effect on resources is that labor moves into the consumption sector.

The benchmark experiment qualitatively reproduces data fluctuations, but produces small effects. We amplify the effects of the basic experiment by a combination of additional shocks and frictions. First, we consider the effects of an additional shock that was a consequence of the region wide economic crisis: the effect of a fall in the demand for Korean exports. A fall in demand for Korean exports makes imported intermediate goods even more expensive. This leads to more resources leaving the investment sector. Second, we consider the effects of working capital requirements on labor demand. Working capital requirements have larger effects on quantities in the investment sector than in the consumption sector. We find that both separately and combined these frictions serve to amplify the underlying mechanism of the model. Combining them, we are able to account endogenously for $30.0 \%$ of the fall in TFP and $41.0 \%$ of the fall in real GDP.

\subsection{Related Research}

To our knowledge, we are among the first to account endogenously for a substantial fall in TFP in a country that experienced a sudden stop. 
Kehoe and Ruhl (2005) propose accounting for TFP falls through a sectoral reallocation from tradable to nontradable production with adjustment costs. Our results are not directly comparable because their division of the economy is different from ours. The movement from manufacturing to agriculture we document in the data is ruled out by their model which combines the two as tradable goods. Of special note to us, Kehoe and Ruhl (2005) show that changes in terms of trade cannot have direct effects on the measurement of productivity in value added at constant prices. We build our story based on indirect effects from an endogenous change to terms of trade.

Benjamin and Meza (2006) model changes in TFP as due to the presence of asymmetric costly financial intermediation across production processes and changes in international interest rates.

Gertler, Gilchrist, and Natalucci (2003) attribute changes to TFP in Korea between 1997 and 1998 to capital utilization. Meza and Quintin (2006) report movements in TFP in a set of countries after recent financial crises. They find that capital utilization can account for at most $40 \%$ of the falls in TFP. We take into account capital utilization when measuring productivity.

Mendoza (2006) conducts a growth accounting exercise for the Mexican crisis of 1994 . He uses a production function for gross output that includes as inputs capital adjusted for capital utilization, labor and imported intermediate goods. He finds that changes in capital utilization and imported intermediate inputs can both account for significant amounts of the falls in gross output. We take into account capital utilization as mentioned above. This leaves the direct effects of imported intermediate inputs. While changes in the usage of imported inputs can affect measured productivity in gross output, they cannot affect measured TFP in value added directly.

Meza and Quintin (2006) also quantify TFP falls using a model of labor hoarding. In their model, the labor input is adjusted by effort. Their method of identifying effort using a one sector model finds it to be a function of the output to labor ratio in aggregate data. As we show in the appendix, a movement from high to low productivity sectors in the data maps into lower measured effort in their model.

There are also many papers that look at the sectoral composition of output in developing economies over time. A growing number of economic papers attempt to explain why factors devoted to agriculture decline while manufacturing and service output increase in the initial stage of development. See the papers cited in Ngai and Pissarides (2006). Our choice of sectors is a particular case of theirs: one consumption and one investment sector.

Finally, a growing number of papers attempts to account for the large and unusual falls in 
GDP that took place after recent financial crises. See Meza and Quintin (2006) for a short survey on this research. Our results are also complementary to related research on the quantitative impact of financial crises. Many of these studies ignore the large falls in TFP associated with financial crises. In the case of Korea, Otsu (2006) has recently found that, in the simplest small open economy model, an exogenous TFP shock can account for most of the fall in GDP. In this paper, we account for much of the fall in TFP. This limits the size of plausible productivity shocks. We report on the behavior of GDP in a model without productivity shocks.

\section{Model-based TFP Measurement and Decomposition}

Our immediate task is to account for the fall in TFP in Korea after its 1997 crisis, net of changes in capital utilization. We decompose TFP into two components: the distribution of resources between sectors and the level of productivity within sectors. To do this we examine productivity in a model with multiple sectors. Our approach closely mirrors Ohanian (2001).

We now describe the model we use for TFP measurement. There are $N$ sectors. Each one produces a different good using capital and labor.

Output in sector $i$ is given by:

$$
y_{i t}=A_{i t} k_{i t}^{\theta_{i}} l_{i t}^{1-\theta_{i}}
$$

where $A_{i t}, k_{i t}$ and $l_{i t}$ are sector $i$ TFP, capital and hours worked, respectively. To compute aggregate real GDP, the sectoral outputs are added using a set of constant prices, $p_{i}$.

Real GDP is:

$$
y_{t}=\sum_{i=1}^{N} p_{i} y_{i t} .
$$

Now consider a one-sector model. This model has a production function of the form:

$$
y_{t}=A_{t} k_{t}^{\theta} l_{t}^{1-\theta}
$$

where $A_{t}, k_{t}$ and $l_{t}$ are aggregate TFP, capital and labor, respectively. Since the two measures of output refer to the same value, the definitions of output imply

$$
A_{t} k_{t}^{\theta} l_{t}^{1-\theta}=\sum_{i=1}^{N} p_{i} A_{i t} k_{i t}^{\theta_{i}} l_{i t}^{1-\theta_{i}} .
$$

Therefore,

$$
A_{t}=\sum_{i=1}^{N} p_{i} A_{i t} \frac{k_{i t}^{\theta_{i}} l_{i t}^{1-\theta_{i}}}{k_{t}^{\theta} l_{t}^{1-\theta}} .
$$


This is an expression for TFP as the combination of relative prices $p_{i t}$, sector specific productivities $A_{i t}$, and a set of weights. Our preference is for weights that sum to one in every period. To do this, we impose two assumptions that create weights with this property. First we assume that the capital income shares, $\theta_{i}$, in each sector are identical. ${ }^{3}$ Second we assume that labor and capital are hired competitively so that the capital to labor ratios are identical across sectors. This produces an approximation for aggregate productivity $A_{t}^{a}$ :

$$
A_{t}^{a}=\sum_{i=1}^{N} p_{i} A_{i t} \frac{l_{i t}}{l_{t}}
$$

where $l_{i t} / l_{t}$ are labor shares.

\subsection{Data}

We take the above definitions of productivity to the data. We use data at a yearly frequency. ${ }^{4}$ We need empirical counterparts of $y_{i t}, l_{i t}, k_{i t}, \theta_{i}, p_{i} A_{i t}, y_{t}, l_{t}, k_{t}, \theta$ and $A_{t}$.

Output per sector $y_{i t}$ is real GDP in per capita terms. The data on GDP by sector is reported at basic prices. We assume the working age population is of age 15 and higher. We divide GDP into nine sectors: 1. agriculture, forestry and fishing; 2. mining; 3. manufacturing; 4. electricity, gas and water supply; 5. construction; 6. wholesale and retail trade, restaurants and hotels; 7. transport, storage and communication; 8. financial services and real estate and 9. public. Public is an aggregation of public administration, health, education and other activities. We label this sector as "public," because this sector contains the public sector and other industries traditionally associated with the provision of public goods. ${ }^{5}$ We choose the base year to be 1997, the year of the crisis. We adjust GDP and investment data by the relevant

\footnotetext{
${ }^{3}$ The capital shares for the nine sectors in the next section are: (1.) Agr., 0.35 (2.) Min., 0.32 (3.) Manuf., 0.29 (4.) Elec., 0.51 (5.) Const., 0.15 (6.) Trade., 0.25 (7.) Trans. 0.30., (8) FIRE, 0.30 and (9) Public., 0.09. To approximate TFP, we also assume that depreciation rates are identical across sectors. We could not find estimates of sectoral depreciation rates for Korea. Horvath (2000) reports quarterly depreciation rates for the US for 36 sectors. Twenty-seven sectors have a rate of $2 \%$. Six sectors have a rate of $1 \%$. Two sectors have a rate of $3 \%$. Construction has the highest rate, $4 \%$.

${ }^{4}$ Our data sources are the National Statistical Office of Korea, www.nso.go.kr and the Bank of Korea, www.bok.or.kr.

${ }^{5}$ In 1997, the share of GDP in this sector for public administration was $34.2 \%$. The share for education was $31.0 \%$. The share for health was $15.8 \%$. In terms of employment, data for 2005 shows that, within education, $67 \%$ of teachers work in public schools as well as $51.8 \%$ of administrative staff.
} 
deflators so that nominal and real variables have the same value in $1997 .^{6}$

We measure labor by sector $l_{i t}$ by computing the total number of hours worked in each sector in per capita terms. We use data on average hours worked in each sector and multiply them by employment data by sector. We measure hours worked relative to total discretionary time available in a year, which we assume is 5200 hours. We construct hours worked up to 2000 because the reporting of data on employment beyond the year 2000 uses a smaller number of categories. ${ }^{7}$ Consequently, we cannot measure TFP by sector past 2000.

Sector specific capital, $k_{i t}$, is constructed using investment data. In this paper, we measure capital utilization by sector. The aim is to eliminate a source of changes in measured TFP. We implement the measurement of variable capital utilization as in Meza and Quintin (2006). ${ }^{8}$ They use the model of Greenwood, Hercowitz, and Huffman (1988) to calculate endogenous utilization and depreciation rates, and capital stocks. ${ }^{9}$ We measure the capital stocks in each sector in per capita terms.

We measure sector-specific capital income shares $\theta_{i}$ using the Korean 1995 input-output matrix. We rearrange the sectors in the matrix into the nine sectors listed above. We adjust labor compensation in each sector taking into account the income of the self-employed. ${ }^{10}$

Using these data, measured TFP in sector $i$ (in terms of base year prices) is:

$$
p_{i} A_{i t}=\frac{y_{i t}}{k_{i t}^{\theta_{i}} l_{i t}^{1-\theta_{i}}}
$$

In the data we observe value. We cannot distinguish price from quantity. Therefore the empirical counterpart of $p_{i}$ is implicit in measured $A_{i t}$. We use these sector specific productivities to calculate approximate TFP, $A_{t}^{a}$.

The empirical counterpart of $y_{t}$ is the sum of sectoral outputs $y_{i t}$. The counterpart of $l_{t}$ is the sum of sectoral labor inputs $l_{i t}$. To construct the counterpart of $k_{t}$ we calculate a stock using

\footnotetext{
${ }^{6}$ Korean data has a given base year of 2000 . We use 1997 prices because they are more relevant to the events of the crisis than 2000 prices.

${ }^{7}$ After this year, the National Statistical Office of Korea reports data for a reduced number of sectors. These sectors are i) Agriculture, forestry and fishing; ii) Mining and manufacturing; iii) Manufacturing and iv) Services.

${ }^{8} \mathrm{We}$ follow the procedure in Meza and Quintin (2006), pp. 20-21, closely. We do not reproduce it here due to its length.

${ }^{9}$ Measuring capital utilization for an economy in transition towards a balanced growth path faces the following difficulty: the capital to output ratios are initially low, compared for example to US values. As a consequence, the depreciation rates implied by the model of Greenwood, Hercowitz, and Huffman (1988) are very high. For some sectors we were not able to construct capital stocks consistent with variable capital utilization because the initial high depreciation rates made stocks very small in a few periods. These sectors are Agriculture, forestry and fishing, Mining, Construction, Wholesale and retail trade, restaurants and hotels.

${ }^{10}$ These adjustments are explained in more detail in the calibration section.
} 
aggregate investment. We use the same procedure as above to measure capital utilization. We assume the aggregate capital income share $\theta$ takes a value of 0.30 . This assumption is supported by Gollin (2002), who finds that after taking into account the income of the selfemployed, labor income shares do not vary much across countries and time, and take values of approximately $70 \%$. We use aggregate data to measure $A_{t}$ in (3), which we call aggregate TFP. $^{11}$

\subsection{Experiments}

Our first question is the accuracy of our approximation of TFP. For this we show two comparisons. First we plot the two raw series in Figure 1. Besides a level difference, the two lines match each other closely, particularly just prior to the crisis. To examine this more closely, we calculate the correlation between first differences of the series. These differences appear in Figure 2. The first differences over the sample show a correlation of 0.91 .

\section{[Insert Figure 1]}

[Insert Figure 2]

To attribute changes in $A_{t}$ to changes in sector specific TFPs or factor reallocation, we carry out a series of counterfactual experiments with $A_{t}^{a}$. For these experiments, we construct alternative approximate TFP series holding constant at their 1997 levels either the sector specific productivities, $p_{i} A_{i t}$, or the labor-related weights. We allow the remaining variables to move as in the data. Our rationale for using approximated TFP instead of aggregate TFP is that the implied weights sum to one in every experiment, which allows for a simple interpretation of results as a weighted arithmetic average.

TFP series depend on two sets of sequences. The first are the labor shares of the individual sectors, which for key sectors are attached as Figure 3. On this figure, a vertical line indicates 1997, the year of the crisis. The second are the sector specific TFPs which are attached for the same sectors as Figure 4. The excluded sectors are quantitatively unimportant to the subsequent analysis.

\section{[Insert Figure 3]}

[Insert Figure 4]

In the aftermath of the crisis, there are sharp falls in the labor shares in manufacturing and construction and sharp increases in the share of labor in agriculture and the public sector. These

\footnotetext{
${ }^{11}$ This measure of TFP fell by 3.3\% between 1997 and 1998, relative to its 1970-1997 average geometric growth rate.
} 
are movements from high to low productivity sectors, as can be seen from Figure 4.

We offer a brief description of the behavior of the sector specific TFP series. Immediately following the crisis, sector specific TFP rose significantly in manufacturing. TFP also rose in construction. TFP fell in agriculture.

Now we report the counterfactual experiments. For the first experiment we analyze the effect of changes in the labor shares. We hold the distribution of labor constant at its 1997 level and allow sector specific TFP data past 1997 to take on its true values. The resulting approximate TFP sequence during the crisis is significantly higher than actual approximate TFP. This is shown in Figure 5. Removing shifts in the composition of labor produces an approximate TFP line that rises slightly after the crisis.

Likewise we can examine the change in approximate TFP that is caused by changes in the productivity of individual sectors by allowing the shares of labor in each sector to change as in the data, but holding productivity within all sectors constant at their 1997 values. In this case, the resulting approximate TFP series is similar to the actual approximate TFP series in 1998.

\section{[Insert Figure 5]}

From the two experiments displayed in Figure 5, we conclude that changes in sector specific TFPs had little role in the fall in aggregate TFP whereas changes in the labor shares have a primary responsibility.

We can adjust the counterfactual hypotheses by allowing elements to follow previous trends rather than remain constant. In particular, we let each labor share grow at its average geometric growth rate. ${ }^{12}$ Regarding sector specific TFPs, we let them grow at the average growth rate across individual TFPs. ${ }^{13}$ The experiments with trends are attached as Figure 6. Note that the order of the lines has not changed. Approximate TFP is higher when labor shares move according to trend than when sector specific TFPs grow according to trend.

\section{[Insert Figure 6]}

We have one more set of results from these exercises that allows to attribute the fall in aggregate TFP to changes in labor for specific sectors. We continue our accounting exercise by repeating the experiments without trends, each time allowing one labor share to move as in the data. Whatever surplus (deficit) labor exists is assigned to the remaining sectors based on their 1997 shares. Sector specific TFPs are held constant. We do this for each of the sectors. We

\footnotetext{
${ }^{12}$ The average is calculated over the entire sample: $1980-2000$.

${ }^{13}$ The average growth rate was calculated using as weights the labor shares in each sector in 1997 . The growth rate is $2.13 \%$. These results are similar to those when TFP series are allowed to grow according to their individual trends. We prefer using the same trend for different sectors because this does not affect the relative difference in levels between sector specific TFPs in any time period.
} 
attach this experiment in Figure 7. This figure allows us to identify the manufacturing sector as the main source for the fall in approximate TFP. Allowing the manufacturing labor share to move erases the effect of holding labor shares constant. This exercise also identifies the reallocation of labor towards the agricultural and public sectors as the other sectors responsible for the fall in approximate TFP. (Visually, the counterfactual approximate TFPs from these two sectors coincide on the graph.) Experiments pertaining to other sectors were excluded from the figure. All excluded experiments lie above the agricultural one. ${ }^{14}$

[Insert Figure 7]

\section{The Model}

In this section we propose a model to account for the observed reallocation of labor after the Korean crisis.

The model has two sectors and, as such, is similar to other international trade models. The novelty of our model is that the sectors are divided into a consumption and an investment sector instead of a tradable and a nontradable sector.

The consumption sector produces a good that has a single use. This sector is modeled after the agricultural and service sectors in the data. Of the sectors identified as important for movements in TFP in the previous section, agriculture and the public sector are contained in the empirical counterpart of this sector.

The investment sector produces a good that can be used for consumption, investment and exporting. We assume that the investment sector uses three inputs: capital, labor and materials. Materials are produced by a sector that uses imported intermediate goods as inputs. Of the sectors identified as important for movements in TFP, manufacturing and construction are contained in the empirical counterpart of this sector. ${ }^{15}$

We introduce a subsidy on production in the consumption sector. The reason for this is that equilibrium productivity differences in levels between sectors are a product of base year prices and technological parameters. In the subsequent calibration, we use this subsidy to match measured productivity differences between sectors before the crisis. The subsidy affects

\footnotetext{
${ }^{14} \mathrm{We}$ have also carried out experiments where we decompose the change in TFP using detrended data. In those experiments we use the trends described in this section. We find that changes in labor allocation remain the largest contributor to changes in TFP. Those results are available upon request.

${ }^{15}$ Our division is not without flaws for quantitatively accounting for changes in TFP. It does combine the low productivity agricultural and public sector with some service sectors that have high productivity, such as financial services.
} 
productivity measurement through its effect on base year prices. ${ }^{16}$

\subsection{Consumer}

The model has a representative consumer with a utility function defined over sequences of consumption goods and leisure. In each time period there are two consumption goods, one from each sector. The good from the consumption sector in period $t$ is denoted $c_{c t}$. The consumption good from the investment sector is denoted $c_{n t}$. The representative consumer splits time between leisure and labor in each of the sectors. Labor allocated to the consumption sector is denoted $l_{c t}$. Labor allocated to the investment sector is denoted $l_{n t}$. The intertemporal utility function is:

$$
\sum_{t=0}^{\infty} \beta^{t} \frac{\left[\left(\phi c_{c t}^{\rho}+(1-\phi) c_{n t}^{\rho}\right)^{\frac{1}{\rho}}\left(1-l_{c t}-l_{n t}\right)^{\eta}\right]^{\omega}-1}{\omega} .
$$

Parameter $\beta$ is the discount factor. Parameter $\omega$ determines the intertemporal elasticity of substitution. Parameter $\rho$ determines the elasticity of substitution between the two consumption goods. Parameter $\phi$ determines the weight of each kind of consumption in the utility function. Parameter $\eta$ determines the weight of leisure in the utility function.

In every period consumers select hours worked, consumption and investment in both sectors. Investment in the consumption sector is denoted $i_{c t}$. Investment in the investment sector is denoted $i_{n t}$. Adjusting either capital stock requires consumers to pay an adjustment cost. The adjustment cost function is $\frac{\psi}{2}\left(k_{j t+1}-k_{j t}\right)^{2}$, where $k_{j t}$ represents the capital stock in sector $j$ and $j \in\{c, n\}$. Consumers also borrow from abroad. Net foreign debt chosen in period $t$ is denoted $b_{t+1}$. A unit of resources lent abroad receives a payment of $r_{t}$, which is the exogenous international interest rate. Consumers receive a wage $w_{j t}$ in each sector. They also receive the rental rate of capital in each sector $r_{j t}$. Consumers' income streams are generated by their capital, labor and interest payments and transfers, $T_{t}$. The relative price of the consumption good is denoted $p_{c t}$. The investment good is the numeraire. Choices satisfy:

$$
\max \sum_{t=0}^{\infty} \beta^{t} \frac{\left[\left(\phi c_{c t}^{\rho}+(1-\phi) c_{n t}^{\rho}\right)^{\frac{1}{\rho}}\left(1-l_{c t}-l_{n t}\right)^{\eta}\right]^{\omega}-1}{\omega}
$$

s. t.

\footnotetext{
${ }^{16}$ Restuccia and Urrutia (2001) use a tax on investment to generate differences in the relative price of investment across countries with similar investment technologies.
} 


$$
\begin{gathered}
p_{c t} c_{c t}+c_{n t}+\sum_{j} i_{j t}+b_{t+1}-\left(1+r_{t}\right) b_{t} \leq \sum_{j} w_{j t} l_{j t}+\sum_{j} r_{j t} k_{j t}+T_{t} \\
i_{j t}=k_{j t+1}-k_{j t}\left(1-\delta_{j}\right)+\frac{\psi}{2}\left(k_{j t+1}-k_{j t}\right)^{2}
\end{gathered}
$$

$j \in\{c, n\}$

$k_{c 0}, k_{n 0}, b_{0}$ given.

\subsection{Production}

We now describe the production side of the model. To ease notation, in what follows we eliminate time subscripts from static equations.

Gross output in the investment sector is produced with a Cobb-Douglas function, requiring three inputs: capital, labor, and materials. Materials are denoted by $m$.

There is a representative firm in the investment sector, which hires its factors of production competitively. The price of materials is $p_{m}$. Optimal allocations in the investment sector solve:

$$
\max y_{n}-r_{n} k_{n}-w_{n} l_{n}-p_{m} m
$$

s. t.

$$
y_{n}=A_{n} k_{n}^{\theta_{k n}} l_{n}^{\theta_{l n}} m^{\theta_{m n}}
$$

Materials are produced by a firm using two inputs: a domestically produced intermediate good, $z$, and an imported intermediate good, $f$. The price of the imported good is $p_{f}$. Materials are produced using an Armington aggregator. Hence the allocation of materials solves:

$$
\max p_{m} m-p_{f} f-z
$$

s. t.

$$
m=M\left(\mu f^{\alpha}+(1-\mu) z^{\alpha}\right)^{\frac{1}{\alpha}}
$$

Parameters in the materials subsector have the following roles. Parameter $\alpha$ determines the elasticity of substitution between domestic and imported inputs. The elasticity of substitution is $\frac{1}{1-\alpha}$. Parameter $\mu$ determines the weight of each input in production. Parameter $M$ is a scale parameter. 
The consumption firm uses two inputs: capital and labor. The technology is Cobb-Douglas. The consumption sector is subsidized by the government with the ad valorem quantity $\tau_{c}$. Allocations in the consumption sector solve:

$$
\max p_{c}\left(1+\tau_{c}\right) y_{c}-w_{c} l_{c}-r_{c} k_{c}
$$

s. t.

$$
y_{c}=A_{c} k_{c}^{\theta_{c}} l_{c}^{1-\theta_{c}} .
$$

\subsection{Export Demand}

The country purchases imports from the rest of the world whom it supplies with exports, $e$. We assume that the rest of the world uses Korean exports as an input for materials in a symmetric problem to the one Korea faces. ${ }^{17}$ This leads to a demand function for exports which satisfies:

$$
e=c_{e}\left(\frac{1}{p_{f}}\right)^{-\frac{1}{1-\alpha}}
$$

where $c_{e}>0$.

\subsection{Market Clearing}

Feasibility in investment and consumption, and the balance of payments equation are:

$$
\begin{gathered}
y_{n}=c_{n}+\sum_{j} i_{j}+e+z \\
y_{c}=c_{c} \\
e_{t}-f_{t} p_{f t}=b_{t+1}-\left(1+r_{t}\right) b_{t} .
\end{gathered}
$$

Finally, we assume that resources used in the subsidy to consumption are taken lump sum from consumers.

$$
T=-\tau_{c} p_{c} y_{c}
$$

\footnotetext{
${ }^{17} \mathrm{We}$ are following Kehoe and Ruhl (2005).
} 


\subsection{Measuring TFP in the Model}

Using model variables, we can calculate the empirical counterparts of real GDP, aggregate TFP $A_{t}$ and approximate TFP $A_{t}^{a}$. We define real GDP in period $t$ at constant 1997 prices as:

$$
p_{c 1997} y_{c t}+y_{n t}-p_{m 1997} m_{t}
$$

Aggregate TFP in period $t$ is:

$$
A_{t}=\frac{p_{c 1997} y_{c t}+y_{n t}-p_{m 1997} m_{t}}{\left(k_{c t}+k_{n t}\right)^{\theta}\left(l_{c t}+l_{n t}\right)^{(1-\theta)}}
$$

Parameter $\theta$ is the aggregate capital share. Approximate TFP $A_{t}^{a}$ in period $t$ is:

$$
p_{c 1997} A_{c} \frac{l_{c t}}{l_{c t}+l_{n t}}+T F P_{n} \frac{l_{n t}}{l_{c t}+l_{n t}} .
$$

TFP in the investment sector equals:

$$
T F P_{n}=\frac{y_{n}-p_{m 1997} m}{k_{n}^{\alpha_{k n}} l_{n}^{1-\alpha_{k n}}} .
$$

Parameter $\alpha_{k n}$ is the capital income share of GDP in the investment sector.

In the next section we calibrate the parameters used to measure TFP in the model.

\section{Calibration}

We calibrate most parameters in the model using the 1995 Korean input-output matrix and Korean national accounts data at a yearly frequency. When used, national product accounts were adjusted to 1997 prices. $^{18}$

We briefly describe how we make the data consistent with the model. The empirical counterpart of the investment sector is the manufacturing and construction sectors. The empirical counterpart of the consumption sector is the remaining sectors. We take out durable goods from consumption and add them to investment in the combined manufacturing and construction sector. We also adjust gross output when the data implies connections between sectors that the model does not. We exclude the flows of intermediate goods within the consumption sector and flows of intermediate goods between the consumption and investment sectors when constructing the empirical counterparts of $y_{n}$, gross output in the investment sector, and $m$, intermediate inputs in the investment sector. When rearranging the input-output matrix, we report measures

\footnotetext{
${ }^{18}$ As mentioned in the measurement section, Korean data has a given base year of 2000 which implies prices that are significantly different than the prices before or during the actual crisis.
} 
of output both at basic and at market prices. We keep track of values at basic prices because the time series on output by industry used in the first part of the paper and in this section are reported at basic prices. We have also adjusted data on compensation of employees by a factor related to the operating surplus of private unincorporated enterprises (OSPUE). Data reported by the United Nations on national income for Korea in 1992 show that the fraction of OSPUE within total operating surplus was $62.7 \%$. We add the corresponding magnitude to compensation of employees in each sector. We attach the modified input-output matrix as Table 1. All values are reported as percentages of total value added at market prices.

We now discuss how individual parameter values are chosen. We begin with income shares. We calibrate all income shares with the modified input-output matrix. Parenthetical numbers refer to items taken from it.

The share of capital income in the consumption sector output, $\theta_{c}$, is equal to operating surplus plus depreciation (14) divided by consumption sector GDP (55).

The share of capital income in the investment sector output, $\theta_{m k}$, is equal to operating surplus plus depreciation (9) divided by investment sector gross output (130). In turn, gross output consistent with our model is the sum of domestic inputs both produced and used in the investment sector (60), value added (36) and imports (34). ${ }^{19}$ Imports are included because they are part of materials, which are the intermediate input used by this sector.

The share of labor income in the investment sector output, $\theta_{m l}$, is equal to compensation of employees (27) divided by investment sector gross output (130).

The share of income that goes to the materials sector, $\theta_{m m}$, is equal to total intermediate inputs divided by investment sector gross output (130). In turn, total intermediate inputs is equal to the sum of domestic inputs (60) which correspond to $z$ in the model, and imports (34), which correspond to $f$ in the model.

Next we turn to the materials sector, starting with the elasticity between imported and domestic inputs. The expression for this elasticity in the model is $\frac{1}{1-\alpha}$. We choose $\alpha=0.5$. The elasticity parameter between imported and domestic intermediate goods has led to a significant debate in the literature. ${ }^{20}$ We borrow the value from Kehoe and Ruhl (2005). This value implies an elasticity of 2 .

We calibrate $\mu$ and $M$ using national accounts data. We use the first order conditions of the firm that produces materials $m$ and the assumption that the price of materials $p_{m}$ and imports $p_{f}$ are one in 1997, the base year. Specifically, let $\gamma=\frac{z}{f}$ and $\lambda=\frac{z}{m}$. The first order condition

\footnotetext{
${ }^{19} \mathrm{We}$ comment on the mapping between imports in the data and imports in the model below.

${ }^{20}$ See Ruhl (2005).
} 
for domestic intermediate inputs, $z$, gives us that

$$
\lambda=\frac{(1-\mu) \gamma^{\alpha}}{\mu+(1-\mu) \gamma^{\alpha}} .
$$

We find $\mu$ from the above equation. To this end, we construct empirical counterparts of $z$ and $f$ from national accounts, in the same way as we did with the input-output matrix. We take $f$ is the value of imports in the economy as a whole. We abstract from the observation that some imports are final goods and that some imported inputs are used by sectors that produce consumption goods. ${ }^{21}$

The scale parameter $M$ is computed from the production function in materials:

$$
m=M\left(\mu f^{\alpha}+(1-\mu) z^{\alpha}\right)^{\frac{1}{\alpha}}
$$

We choose the depreciation rate of capital in the investment sector, $\delta_{n}$, to equal $5 \%$. We set the value of the depreciation rate in the consumption sector, $\delta_{c}$ equal to $4 \%$. We have two observations in mind for these choices. First, Horvath (2000) provides evidence that depreciation rates are higher in construction and manufacturing than in agriculture and services. Second values around $5 \%$ are frequently used in one sector models.

Next we turn to export demand. We calibrate $c_{e}$ using national accounts data. We use the equation for export demand, assuming again that the price of imports $p_{f}$ is one in 1997. With this assumption, the export demand function simplifies to $e=c_{e}$. We choose total exports in 1997 from national accounts as the empirical counterpart of $e .^{22}$

We choose the value of $\psi$, the capital adjustment cost parameter, such that the model converges to a steady state in 25 periods in the benchmark experiment.

Next we turn to parameters in the utility function. We choose the value of $\phi$ with data from the input-output matrix. As we discuss shortly, we assume a logarithmic utility function. With such function, $\phi$ corresponds to the ratio of expenditure on consumption of the consumption sector good relative to total expenditure. We choose household plus government consumption

\footnotetext{
${ }^{21}$ Data from the Korean 1995 Transaction Table of Imported Goods and Services shows that in that year 71.6\% of all imports were intermediate inputs. Also, the Bank of Korea (1998) reports the ratio of import dependence by sector, which is the ratio of imported intermediate inputs to the sum of domestic intermediate inputs and value added. The manufacturing sector has the highest dependency ratio: $18.0 \%$. Calculating this ratio for the empirical counterparts of the model, we find that the ratio is $4.7 \%$ in the consumption sector and $15.5 \%$ in the investment sector.

${ }^{22}$ The share of exports from the investment sector in the data is 0.806 . It is also common in related research to allow agriculture to produce a good that is exported. In the data agricultural, forestry and fishery exports have a share of 0.0083 .
} 
expenditure of agricultural goods and services (which is 44 in the matrix) as the empirical counterpart of expenditure on the consumption sector good in the model. Regarding total expenditure, we choose household plus government consumption expenditure on all goods except for durable goods (59) as the empirical counterpart of total expenditure in the model.

We choose standard values for other parameters in the utility function. We set the values of $\omega$ and $\rho$ such that period utility is $\phi \ln \left(c_{c}\right)+(1-\phi) \ln \left(c_{n}\right)+\eta \ln \left(1-l_{c}-l_{n}\right)$. We set the value of $\beta$ equal to $1 /(1+r)$, where $r$ is the long run value of the real interest rate on foreign debt. We discuss the choice for this value in the description of the benchmark experiment.

The parameter which governs the disutility from labor, $\eta$, is chosen to match observed aggregate hours worked in the initial period in the experiments: $30 \%$ of available discretionary time, which we assume to be equal to 5200 hours in a year. This is approximately the observed value in $1994 .^{23}$

Finally we calibrate the productivity parameters. We calibrate $A_{c}$ and $A_{n}$ from the definitions of value added in the consumption sector and gross output in the investment sector, respectively. ${ }^{24}$ We use time series for $y_{c}, y_{n}, l_{c}, l_{n}, m, k_{c}$ and $k_{n}$. Again, we use the same division of the data which we use in the model. In particular, our empirical counterpart of labor in the investment sector, $l_{n}$, is the sum of the labor inputs calculated for manufacturing and construction in the first part of the paper. The empirical counterpart of $l_{c}$ is the sum of the rest of the sectoral labor inputs.

We detrend the empirical counterparts of outputs $y_{c}, y_{n}, l_{c}, l_{n}$ and $m$ using the HodrickPrescott filter. Given that our accounting for TFP is based on differences in levels (as can be seen in the formula for approximate TFP), we calculate the Hodrick-Prescott trend, then use it to detrend the variables keeping fixed their level in $1997 . .^{25}$

We now turn to the construction of capital stocks. Here we follow closely the procedure in Meza and Quintin (2006), who measure time series of TFP net of capital utilization. ${ }^{26}$ We calculate recursively utilization rates, depreciation rates and time series of capital stocks. To

\footnotetext{
${ }^{23}$ Parameters calibrated to match 1994 targets have very similar values if calibrated to match 1997 targets. This applies to $\eta, A_{c}$ and $A_{n}$.

${ }^{24}$ Parameter $A_{n}$ is not the empirical counterpart of TFP in the investment sector, because $y_{n}$ is gross output, not value added.

${ }^{25}$ We decide to detrend the empirical counterparts of model variables because in our model there is no growth in the long run, whereas Korean data does display it. In the next section, we describe how we compare model outcomes and detrended data on all variables. We detrend each empirical counterpart as described in the previous paragraph.

${ }^{26}$ This is the same method used in the measurement section, except in that case we had nine sectors instead of two. Again we leave out specific details and refer the reader to Meza and Quintin (2006).
} 
do this, we use per capita data in levels on the empirical counterparts of outputs $y_{c}$ and $y_{n}$, investments $i_{c}$ and $i_{n}$, and values for initial capital stocks $k_{c 0}$ and $k_{n 0}$. Then we calculate the effective capital for each sector, the product of the utilization rate and the capital stock. We then detrend effective capital. Our empirical counterpart of $k_{c}$ and $k_{n}$ is detrended effective capital in each sector.

Having constructed empirical counterparts of variables in the model, we assign values to $A_{c}$ and $A_{n}$. We use observations for 1994, because the initial period in our experiments corresponds to this year. To calibrate TFP in the consumption sector, we assume that $p_{c 1997}$ in the the data. We calculate

$$
A_{c}=\frac{y_{c}}{k_{c}^{\theta_{c}} l_{c}^{1-\theta_{c}}}
$$

To calibrate $A_{n}$, we calculate

$$
A_{n}=\frac{y_{n}}{k_{n}^{\theta_{k n}} l_{n}^{\theta_{l n}} m^{\theta_{m n}}} .
$$

To calculate TFP in the investment sector, we use data on GDP consistent with our model and the constructed capital and labor inputs. Measured TFP in the investment sector equals:

$$
T F P_{n}=\frac{G D P_{n}}{k_{n}^{\alpha_{k n}} l_{n}^{1-\alpha_{k n}}} .
$$

In this expression, $\alpha_{k n}$ is the share of capital income in GDP in the investment sector. We calibrate this share by dividing capital income in this sector (9) by GDP (36).

To measure aggregate TFP $A_{t}$ in the model, we need the value of the aggregate capital income share $\theta$. As in the empirical part of the paper, we assume a value of $0.30 .{ }^{27}$

Finally we calibrate the subsidy to the consumption sector, $\tau_{c}$. We choose its value to match the ratio $\frac{T F P_{n}}{p_{c} A_{c}}$ from the data in 1997 , before the crisis. The value of the ratio we target is $1.45 .^{28}$ The interpretation is that the empirical counterpart of the model investment sector is $45 \%$ more productive than the counterpart of the consumption sector.

We summarize the calibration procedure and the values chosen in Table 2.

\section{Experiments}

In this section, we analyze the behavior of labor, productivity and output along a transition path that is interrupted by a crisis. The initial period corresponds to 1994 . We choose this year because available data on interest spreads begins in that year. We set the initial capital stock in

\footnotetext{
${ }^{27}$ If we use the input-output matrix to calibrate $\theta$, we find a value close to 0.30 .

${ }^{28} \mathrm{We}$ have assumed in the data that $p_{c 1997}=1$ and $p_{m 1997}=1$. In our baseline experiment $p_{c 1997}=1.02$ and $p_{m 1997}=0.99$.
} 
each sector to match the Korean economy in 1994. Also, we choose an initial level of foreign debt such that the debt to real GDP ratio is equal to $11 \%$ in $1997 .{ }^{29}$

As a baseline, the crisis is represented by an unanticipated sudden stop, precluding any new borrowing from the rest of the world for two periods. Simultaneously, the economy also faces an unanticipated sequence of higher interest rates.

We compare detrended data with detrended model outcomes. We detrend model outcomes in the same way we detrended the data, with the Hodrick-Prescott filter. We do this because even though the model does not display long run growth, there is a transition towards a steady state. We eliminate the effects of this transition.

\subsection{Benchmark}

Our baseline experiment is an unanticipated sudden stop together with an unanticipated increase in interest rates. The sudden stop consists of eliminating any new foreign borrowing for two periods. These periods correspond to 1998 and 1999 in the data. To construct the sequence of interest rates, we follow Meza and Quintin (2006). ${ }^{30}$ In the experiment, we assume that the values of interest rates are perfectly anticipated with one exception. The initial expectation of interest rates for 1998 and subsequent periods is to match their 1994-1997 average in the data. This value is $3.7 \%$. After 1998 all expectations for interest rates are accurate and match the data. $^{31}$

Before displaying the results, we discuss the intuition behind them. The sudden stop of capital inflows requires the economy to switch from negative to positive net exports. The economy faces a downward sloping demand curve for its exports. As the economy is forced to increase exports, their price, relative to the price of intermediate imported goods, falls. The increase in the price of imports has a negative impact on the investment sector, reducing the amount of labor it uses.

At the same time, there is a second effect that assists in the resource movements we document. Investment falls sharply as international interest rates rise. This drives down the demand for investment goods as resources used in investment can alternatively be sent abroad. Even though exports increase as a result of the crisis, the fall in the remaining uses of investment

\footnotetext{
${ }^{29}$ Korea had a debt to GDP ratio of $11 \%$ in 1997, as reported by Lane and Milesi-Ferretti (2006).

${ }^{30} \mathrm{We}$ use data on interest rates on US Treasury bills, US inflation and a spread of Korean debt to calculate a real international interest rate.

${ }^{31} \mathrm{We}$ solve the model assuming that a steady state is reached in finite time. This assumption provides us with a system of nonlinear equations that we solve numerically.
} 
goods is significantly larger. The overall result is a movement of resources, particularly labor, from the investment to the consumption sector.

Because resources move into a less productive sector, the model is qualitatively able to reproduce the behavior of key variables in the data after the Korean crisis. In the benchmark experiment, both aggregate and approximate TFP fall. Real GDP and total labor also fall.

The behavior of total labor is unusual for a model of a sudden stop. We provide some intuition for its behavior. In a one sector model, Chari, Kehoe, and McGrattan (2005) show that the negative income effect due to the sudden stop leads to an increase in total labor supply. The income effect is different in the investment sector of this model. The equilibrium condition on labor in the investment sector is:

$$
l_{n}\left(1+\frac{\eta}{(1-\phi) \theta_{n l}} \frac{c_{n}}{y_{n}}\right)=\left(1-l_{c}\right) .
$$

Labor in the investment sector depends on the ratio of investment sector consumption to investment sector gross output $\frac{c_{n}}{y_{n}}$, and on labor in the consumption sector. The income effect works through the consumption to output ratio. In our benchmark experiment, this ratio increases as investment falls. The income effect leads to downward pressure on labor in the investment sector.

Labor in the consumption sector in equilibrium satisfies:

$$
l_{c}\left(1+\frac{\eta}{\phi\left(1-\theta_{c}\right)\left(1+\tau_{c}\right)} \frac{c_{c}}{y_{c}}\right)=\left(1-l_{n}\right) .
$$

The ratio of consumption to output in the consumption sector is always equal to one. This eliminates from this sector any income effect. The coefficient that relates $l_{c}$ and $\left(1-l_{n}\right)$ in this last equation is strictly positive because the two labors are perfect substitutes. Therefore, adjustments to $l_{c}$ and $l_{n}$ after a sudden stop are negatively correlated, though movements in $l_{c}$ are much smaller.

The key predicted outcomes are attached in Figures 8 and 9. All variables have been indexed to take a value of 1 in 1997. In Figure 8 we compare data and predictions for aggregate TFP, approximate TFP, labor in both sectors and real GDP. These variables are the main focus of the paper. The effects are qualitatively correct but small.

In Figure 9 we compare data and predictions on other variables: exports, imports, terms of trade and investment. In two aspects, the results of the numerical experiments are not qualitatively consistent with the data. The model predicts both a large increase in exports and a significant worsening of the terms of trade for Korea in 1998. In 1998, neither showed much movement in the data. 


\subsection{Shock to Export Demand}

Our second experiment adds an additional shock to increase the cost of imported intermediate inputs. The shock we use is a fall in export demand. This shock increases the driving force behind our mechanism, which is that higher import prices force resources into less productive sectors.

We again shock the economy with an unanticipated sudden stop and an increase in interest rates. In addition, we assume a fall in export demand that leads to a corresponding worsening of Korea's equilibrium terms of trade. We do this by exogenously reducing the parameter $c_{e}$ in the export demand function. ${ }^{32}$ Our target for this change is to match the actual level of exports demanded from the Korean economy in 1998. The shock to export demand captures directly the fall in demand for Korean goods due to the region wide nature of the Asian financial crisis, particularly the fall in demand from Japan.

Quoting Ghosh, Harmann, Lane, Phillips, Schultze-Ghattas, and Tsikata (1999):

"Growth of export volumes was dampened by further shocks to external demand notably associated with the slowing of economic activity from Japan".

The results from this experiment are qualitatively similar to our previous results, but are quantitatively larger. They are attached as Figures 10 and 11 . The fall in aggregate TFP is now $19.3 \%$ of the actual fall in aggregate TFP and the fall in approximate TFP is also larger. This is because with fewer, more expensive imports the movements in labor are larger. In particular, we see that the fall in labor in the investment sector is closer in magnitude to the observed fall in the data than in the benchmark experiment. The model accounts for $37.6 \%$ of the fall in labor in the investment sector. The model can also account for $14.8 \%$ of the fall in real GDP.

This experiment captures $60.4 \%$ of the fall for imports demanded by the Korean economy in the data. A larger shock could potentially capture more of the fall. We ran an additional experiment matching the fall in imports in the data. In this experiment, the fall in TFP was $39.7 \%$ of the fall in the data.

\subsection{Shocks to the cost of working capital}

In this experiment we use our original interest rate shocks but introduce an amplification mechanism. Specifically, we add working capital requirements as in Neumeyer and Perri (2005). In the experiment, the addition of working capital requirements decreases labor supply in both

\footnotetext{
${ }^{32}$ Cavallo, Kisselev, Perri, and Roubini (2005) study financial crises with a shock to export demand.
} 
sectors, but decreases labor supply in the investment sector more than in the consumption sector.

Working capital requirements require a change on the production side of the economy. We modify the benchmark experiment by requiring firms in both sectors to borrow for the wage bill in advance of production. Firms must set aside $w_{j} l_{j}$ at the beginning of each period to hire $l_{j}$. In the process they forgo the opportunity to earn any interest on resources set aside so that the cost to the firm of hiring $l_{j}$ is $w_{j}(1+r) l_{j}$. The interest revenues are then collected and returned to consumers in a lump sum manner. With this modification, profits in the consumption sector equal:

$$
p_{c}\left(1+\tau_{c}\right) y_{c}-w_{c}(1+r) l_{c}-r_{c} k_{c} \text {. }
$$

In the investment sector, profits equal:

$$
y_{n}-r_{n} k_{n}-w_{n}(1+r) l_{n}-p_{m} m .
$$

Results can be seen in Figures 12 and $13 .{ }^{33}$ In our experiment, both labor in consumption and labor in investment fall, as in the data. Labor in investment falls 7.5\%. Labor in consumption falls $2.4 \%$. The effects of working capital are larger in the investment sector than in the consumption sector. The reason for this is that the consumer reduces capital accumulation, because of consumption smoothing in response to working capital shocks. The model can account for $62.4 \%$ of the fall in labor in the consumption sector and $45.2 \%$ of the fall in labor in the investment sector.

Working capital requirements increase the fall in TFP relative to the benchmark. In Figure 12, we see that measured TFP now falls $17.9 \%$ of fall in TFP experienced in the data. Additionally, the model can account for $31.5 \%$ of the fall in GDP. ${ }^{34}$

Working capital requirements also improve the performance of the model relative to the benchmark in terms of exports and terms of trade. These results are displayed in Figure 13. Though exports still increase and the terms of trade worsen, both do so by a much smaller amount than in the benchmark experiments. This is because, with the increase in the cost of labor in the investment sector, it is more costly to increase exports.

\footnotetext{
${ }^{33}$ Because we are modifying the model, we recalibrate $\tau_{c}$ and the initial debt to continue matching previous targets.

${ }^{34}$ Neumeyer and Perri (2005) show that the addition of working capital requirements produces large falls in output when interest rates rise.
} 


\subsection{Combined Experiment}

We conclude the paper with an experiment that combines all of the effects studied so far. We view this experiment as containing our main results. To conduct this experiment we add both the shock to export demand and the working capital requirements to the benchmark experiment. The results are attached as figures 14 and 15.

The results in this experiment are qualitatively similar to the previous experiment, but the effects are larger. Labor in both sectors falls. The model can account for $53.2 \%$ of the fall in labor in the consumption sector and for approximately $67.7 \%$ of the fall in labor in the investment sector. In the case of TFP and GDP, the model can account for $30.0 \%$ and $41.0 \%$ of the respective falls.

The model can account for $63.8 \%$ of the fall in imports. On the negative side, immediately after the crisis, the terms of trade worsen by a substantial amount. Finally, the model predicts a larger fall in investment than in the data and the previous two experiments.

\subsection{Sensitivity Analysis}

In this section, we report the results of the model under alternative parameter values. Particularly, we are interested in different values for the elasticities implied by the model. The three elasticities we vary are the elasticity with regard to imported intermediate goods, which is governed by $\alpha$, the elasticity between the consumption goods, governed by $\rho$, and the intertemporal elasticity, governed by $\omega$. We measure the sensitivity of results in the combined experiment.

We vary the trade elasticity in both directions. Our baseline calibration gives an elasticity of 2 . We consider two alternative possibilities, $\alpha=\left\{\frac{1}{10}, \frac{3}{4}\right\}$. This implies elasticities of $\frac{10}{9}$ and 4. The results from this and all subsequent experiments are attached in Table 3. The effects are significant for both experiments with $\alpha$. However, they are more pronounced the smaller $\alpha$ is. This is because as foreign imported intermediate goods and domestic intermediate goods become more complementary, the rise in the cost of imports has a bigger effect.

The second parameter we consider is the elasticity between consumption goods. There is little evidence on this elasticity. Our baseline elasticity is 1.0 which comes from a choice of $\rho=0$. We consider alternatively parameter values for $\rho=\left\{\frac{-2}{3}, \frac{1}{3}\right\}$. These imply elasticities of $\frac{3}{5}$ and $\frac{3}{2}$ respectively. Neither affects outcomes significantly.

We also run sensitivity analysis over $\omega$. In the literature, a frequent value of the implied intertemporal elasticity is $\frac{1}{2}$. This corresponds to $\omega=-1$. Lowering $\omega$ does reduce the size of the effects we report in our preferred calibration. TFP falls by a smaller amount. Labor 
in the consumption sector falls by more and labor in the investment sector falls by less. The reason for this is a substitution effect. Overall, consumption falls because of an income effect. The substitution effect works against the fall in current consumption. The substitution effect is determined by the price of the consumption sector good today relative to the price tomorrow, $\frac{p_{a t}}{p_{a t+1}}$. This ratio falls unexpectedly in 1998 as result of the crisis and rising import prices. When $\omega$ is high, the consumer substitutes more consumption today for consumption tomorrow. When $\omega$ is low, the consumer does not lower investment as much to take advantage of the relatively cheaper price for today's consumption sector good.

\section{Conclusion}

In this paper we first show evidence that the fall in TFP in Korea in 1998 is related to a reallocation of labor from a high productivity sector, manufacturing, to low productivity sectors, especially agriculture and the public sector. We then suggest a mechanism that accounts for both the sectoral reallocation and the fall in TFP in response to a sudden stop and an increase in international interest rates. Our mechanism has two parts. First is the rise in the cost of imported intermediate goods which are used predominantly in manufacturing. Second is the fall in investment due to an increase in international interest rates.

Using a two-sector model, we have measured the quantitative impact of the sudden stop combined with two additional shocks: a fall in export demand and an increase in the cost of working capital. These forces can account for $30.0 \%$ of the fall in measured TFP after the crisis. The mechanism can also account for $41.0 \%$ of the fall in real GDP.

We highlight one more point. Our analysis is conducted through a two sector small open economy model with a consumption and an investment sector. This divide of the economy contributes to reproducing the fall of aggregate labor. This is true even without working capital requirements. There is no negative income effect on the supply of labor in the consumption sector. Labor in the investment sector falls as the price of imports and international interest rates rise. Consequently all our experiments predict a fall in aggregate labor. 


\section{Appendix: The Relationship between Sectoral Reallocation and Labor Hoarding}

In this appendix, we derive a relationship between our model and another model in the literature used to account for a large fall in TFP in the case of the Mexican 1994 crisis.

Meza and Quintin (2006) model labor hoarding in a one sector model. Labor hoarding allows the effort employees choose to adjust freely, while employment is costly to adjust.

The model can be used to measure TFP net of effort. Effort is unobservable to the economist so it is measured through the model. In their model, TFP net of effort is,

$$
T F P_{t}=\frac{y_{t}}{k_{t}^{\theta}\left(l_{t} \epsilon_{t}\right)^{1-\theta}},
$$

where $\epsilon_{t}$ represents effort. Variable $y_{t}$ represents a measure of output, $k_{t}$ is aggregate capital (which can be adjusted for utilization) and $l_{t}$ is aggregate labor.

Equilibrium effort is equal to

$$
\epsilon_{t}=\left(\frac{1-\theta}{f^{\nu-1}} \frac{y_{t}}{l_{t}}\right)^{\frac{1}{\nu}},
$$

where $\theta$ is the aggregate capital income share, $\nu>1$ determines the wage-elasticity of effort and $f>0$ is the average number of hours worked per worker. Both $\nu$ and $f$ are parameters in their model.

We now link this formula on effort to our research. Remember from a multi-sector model that:

$$
y_{t}=\sum_{i} p_{i} A_{i t} k_{i t}^{\theta_{i}} l_{i t}^{1-\theta_{i}}
$$

We combine the last two equations to get:

$$
\epsilon_{t}=\left(\frac{1-\theta}{f^{\nu-1}} \frac{\sum_{i} p_{i} A_{i t} k_{i t}^{\theta_{i}} l_{i t}^{1-\theta_{i}}}{\sum_{i} l_{i t}}\right)^{\frac{1}{\nu}} .
$$

From here, we reinstate our assumptions in the measurement section that capital income shares and depreciation rates are identical across sectors, and that factor markets are perfectly competitive. Thus, sectoral capital to labor ratios are identical. It follows that

$$
\epsilon_{t}=\left(\left(\frac{1-\theta}{f^{\nu-1}}\right)\left(\left(\frac{k_{t}}{l_{t}}\right)^{\theta}\right)\left(\sum_{i} p_{i} A_{i t} \frac{l_{i t}}{l_{t}}\right)\right)^{\frac{1}{\nu}} .
$$

There are three terms here. The first is a constant. The second is the aggregate capital to labor ratio. In the case of Korea, this ratio grows after the crisis. Therefore, it cannot account for the 
fall in TFP after the crisis. The third term is our term for approximate TFP. In the case under study, we have already shown that changes in this term are due primarily to movements from high productivity sectors to low productivity sectors. Labor reallocation in the data leads to changes in measured effort.

\section{References}

Benjamin, D., AND F. MeZA (2006): "Productivity and Interest Rates in an Economy with Financial Frictions: Facts and a Theory," University of Southampton Working Paper.

Cavallo, M., K. Kisselev, F. Perri, and N. Roubini (2005): "Exchange Rate Overshooting and the Cost of Floating," Federal Reserve Bank of San Francisco Working Paper.

Chari, V., P. J. Kehoe, and E. McGrattan (2005): "Sudden Stops and Output Drops," in American Economic Review, Papers and Proceedings, no. 2, pp. 381-387.

Gertler, M., S. Gilchrist, and F. NatalucCi (2003): "External Constraints on Monetary Policy and the Financial Accelerator," NBER Working Paper 10128, forthcoming Journal of Money, Credit and Banking.

Ghosh, A., J. Harmann, T. Lane, S. Phillips, M. Schultze-Ghattas, and T. TsiKATA (1999): “IMF-Supported Programs in Indonesia, Korea, and Thailand: A Preliminary Assessment," IMF Occassional Paper 178.

Gollin, D. (2002): “Getting Income Shares Right,” Journal of Political Economy, 110, 458474.

Greenwood, J., Z. Hercowitz, and G. Huffman (1988): "Investment Capacity Utilization and the Real Business Cycle," American Economic Review, 78(3), 402-417.

Horvath, M. (2000): "Sectoral Shocks and Aggregate Fluctuations," Journal of Monetary Economics, 45(1), 69-106.

Kehoe, T. J., And K. J. Ruhl (2005): “Sudden Stops, Sectorial Reallocations and the Real Exchange Rate," Working Paper.

LAne, P., And G. M. Milesi-Ferretti (2006): "The External Wealth of Nations Mark II: Revised and Extended Estimates of Foreign Assets and Liabilities,1970-2004," IMF Working Paper. 
MendozA, E. G. (2006): "Endogenous Sudden Stops in a Business Cycle Model with Colateral Constraints: A Fisherian Deflation of Tobin's Q," University of Maryland Working Paper.

MeZA, F., And E. Quintin (2006): “Financial Crises and Total Factor Productivity,” Federal Reserve Bank of Dallas Working Paper.

Neumeyer, P., And F. Perri (2005): "Business cycles in emerging economies: the role of interest rates," Journal of Monetary Economics, 52, 345-380.

NGAI, R., AND C. PISSARIDES (2006): "Structural Change in a Multi-Sector Model of Economic Growth," Forthcoming in American Economic Review.

Ohanian, L. (2001): "Why Did Productivity Fall So Much During the Great Depression?," in American Economic Review, Papers and Proceedings, pp. 34-38.

OTSU, K. (2006): “A Neoclassical Analysis of the Korean Crisis,” IMES, Bank of Japan Working Paper.

Restuccia, D., And C. UrRutia (2001): “Relative Prices and Investment Rates,” Journal of Monetary Economics, 47, 93-121.

RuHL, K. (2005): “The Elasticity Puzzle in International Economics," University of TexasAustin Working Paper. 


\section{Table 1: Input-Output Matrix}

\begin{tabular}{|c|c|c|c|c|c|c|c|c|}
\hline Commodity & Inv. sector & $\begin{array}{r}\text { Input } \\
\text { Cons. sector }\end{array}$ & Total & Cons. & $\begin{array}{c}\text { Final } \\
\text { Inv. }\end{array}$ & $\begin{array}{l}\text { demand } \\
\text { Exports }\end{array}$ & Imports & $\begin{array}{c}\text { Value added } \\
\text { m.p. }\end{array}$ \\
\hline Inv. sector & 60 & 14 & 74 & 14 & 42 & 24 & 26 & 55 \\
\hline Cons. sector & 27 & 24 & 50 & 44 & 3 & 6 & 8 & 45 \\
\hline Total intermediate cons. & 87 & 37 & 124 & 59 & 45 & 30 & 34 & 100 \\
\hline Employee compensation & 27 & 42 & 68 & & & & & \\
\hline Return to capital & 9 & 14 & 23 & & & & & \\
\hline Net indirect taxes & 6 & 2 & 8 & & & & & \\
\hline Value added b.p. & 36 & 55 & 92 & & & & & \\
\hline Value added m.p. & 42 & 58 & 100 & & & & & \\
\hline Imports & 34 & & & & & & & \\
\hline Gross output b.p. & 130 & 93 & & & & & & \\
\hline Gross output m.p. & 136 & 95 & & & & & & \\
\hline
\end{tabular}


Table 2: Parameters

\begin{tabular}{|l|l|l|}
\hline & Value & Source \\
\hline \hline$\theta_{c}$ & 0.2496 & Input-Output Matrix (I-O) \\
$\theta_{k n}$ & 0.0723 & I-O \\
$\theta_{l n}$ & 0.2066 & I-O \\
$\mu$ & 0.4300 & I-O \\
$M$ & 1.9600 & National Accounts \\
$\phi$ & 0.7538 & National Accounts \\
$\delta_{c}$ & 0.0500 & Depreciation rate \\
$\delta_{n}$ & 0.0400 & Depreciation rate \\
$c_{e}$ & 0.0045 & Level of exports 1994 \\
$\beta$ & 0.9643 & Real international interest rate=3.7\% \\
$\rho$ & 0.0001 & Logarithmic case \\
$\omega$ & 0.0001 & Logarithmic case \\
$\eta$ & 2.7000 & Match labor level=30\% in 1994 \\
$\alpha$ & 0.5000 & Kehoe-Ruhl (2005) \\
$\psi$ & 35.000 & Convergence to steady state, 25 periods \\
$A_{c}$ & 0.0603 & Productivity level 1994 \\
$A_{n}$ & 0.9168 & Productivity level 1994 \\
$\tau_{c}$ & 1.3800 & Match productivity differences pre-crisis \\
$\alpha_{k n}$ & 0.2590 & I-O \\
$\theta$ & 0.3000 & Gollin (2002) \\
\hline
\end{tabular}




\section{Table 3: Sensitivity Analysis,}

\section{Percentage of Change in Data Accounted For}

\begin{tabular}{|l|cccccc|}
\hline & \multicolumn{7}{|c|}{ Experiment } \\
Observation & Main & $\alpha=\frac{1}{10}$ & $\alpha=\frac{3}{4}$ & $\rho=\frac{-2}{3}$ & $\rho=\frac{1}{3}$ & $\omega=-1$ \\
\hline \hline TFP & 30.0 & 30.3 & 19.6 & 27.2 & 31.1 & 23.0 \\
GDP & 41.0 & 43.0 & 31.7 & 41.9 & 40.5 & 34.6 \\
Labor in Cons. & 53.2 & 51.7 & 61.8 & 56.9 & 49.1 & 60.2 \\
Labor in Inv. & 67.7 & 73.1 & 46.1 & 60.1 & 77.6 & 51.5 \\
Investment & 143.8 & 120.8 & 167.8 & 143.4 & 146.8 & 144.5 \\
Imports & 63.8 & 54.3 & 83.4 & 55.1 & 74.6 & 67.0 \\
\hline
\end{tabular}


Figure 1: Aggregate and Approximate TFP: Levels

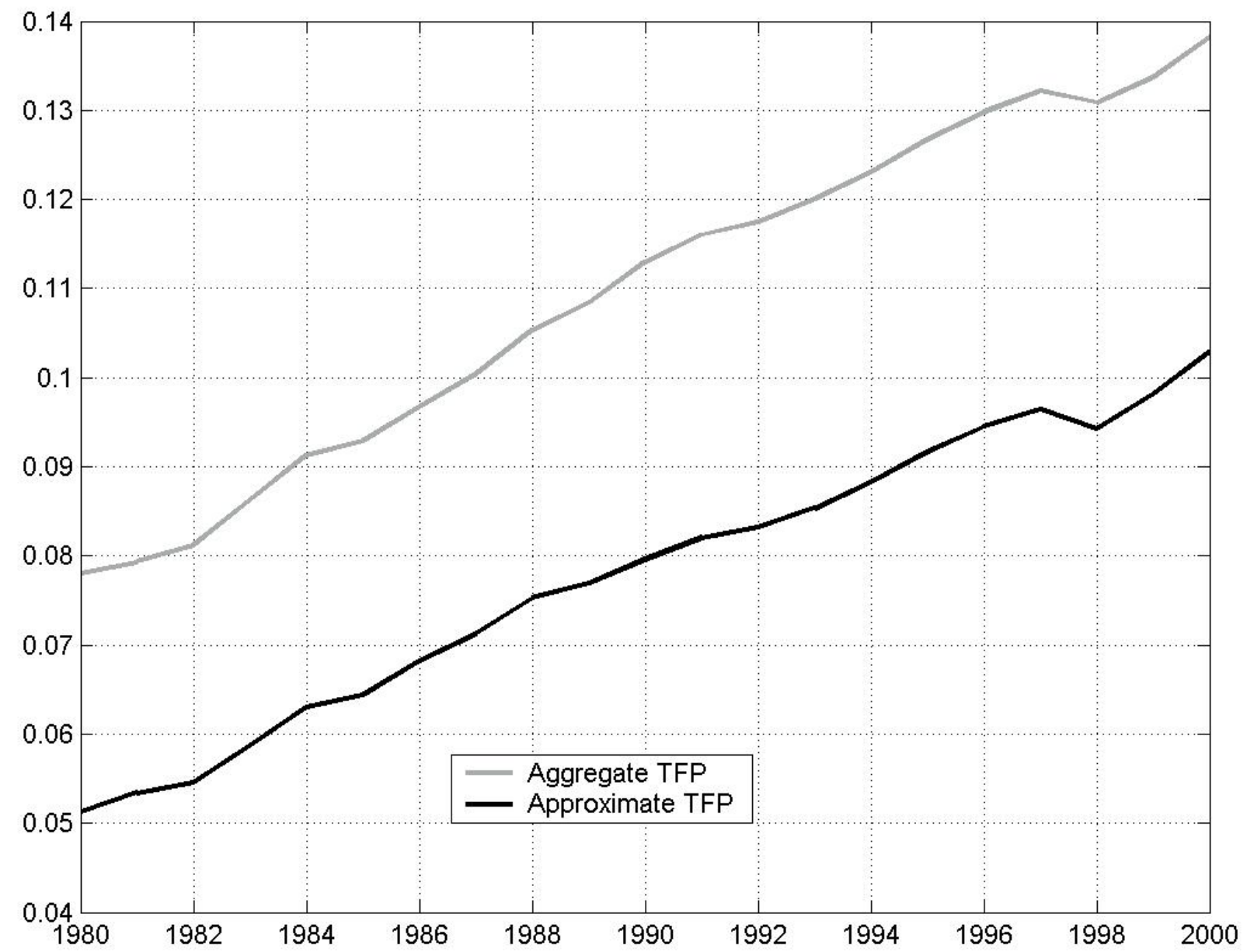


Figure 2. Aggregate and Approximate TFP: First Differences

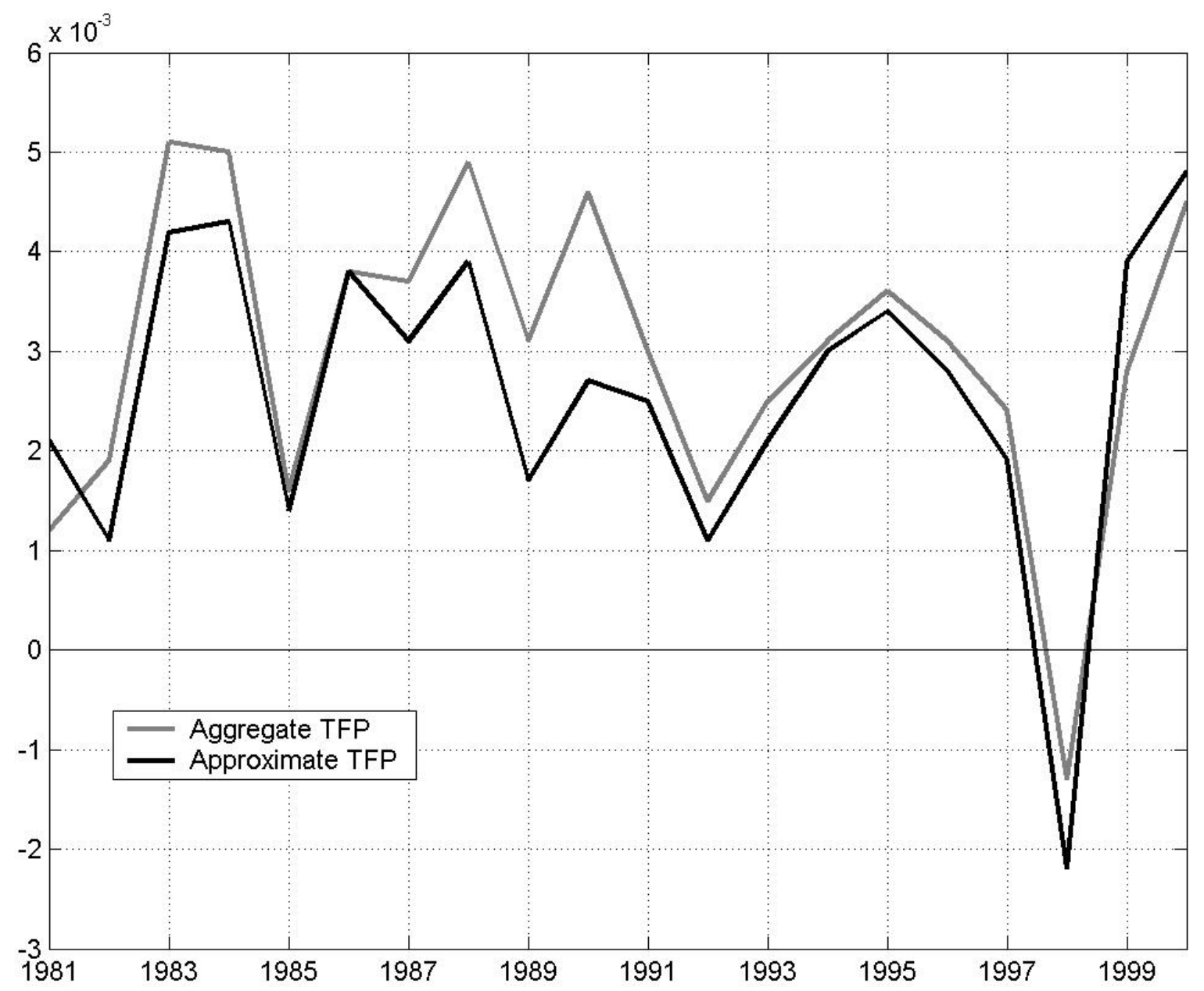


Figure 3. Labor Shares, Key Sectors

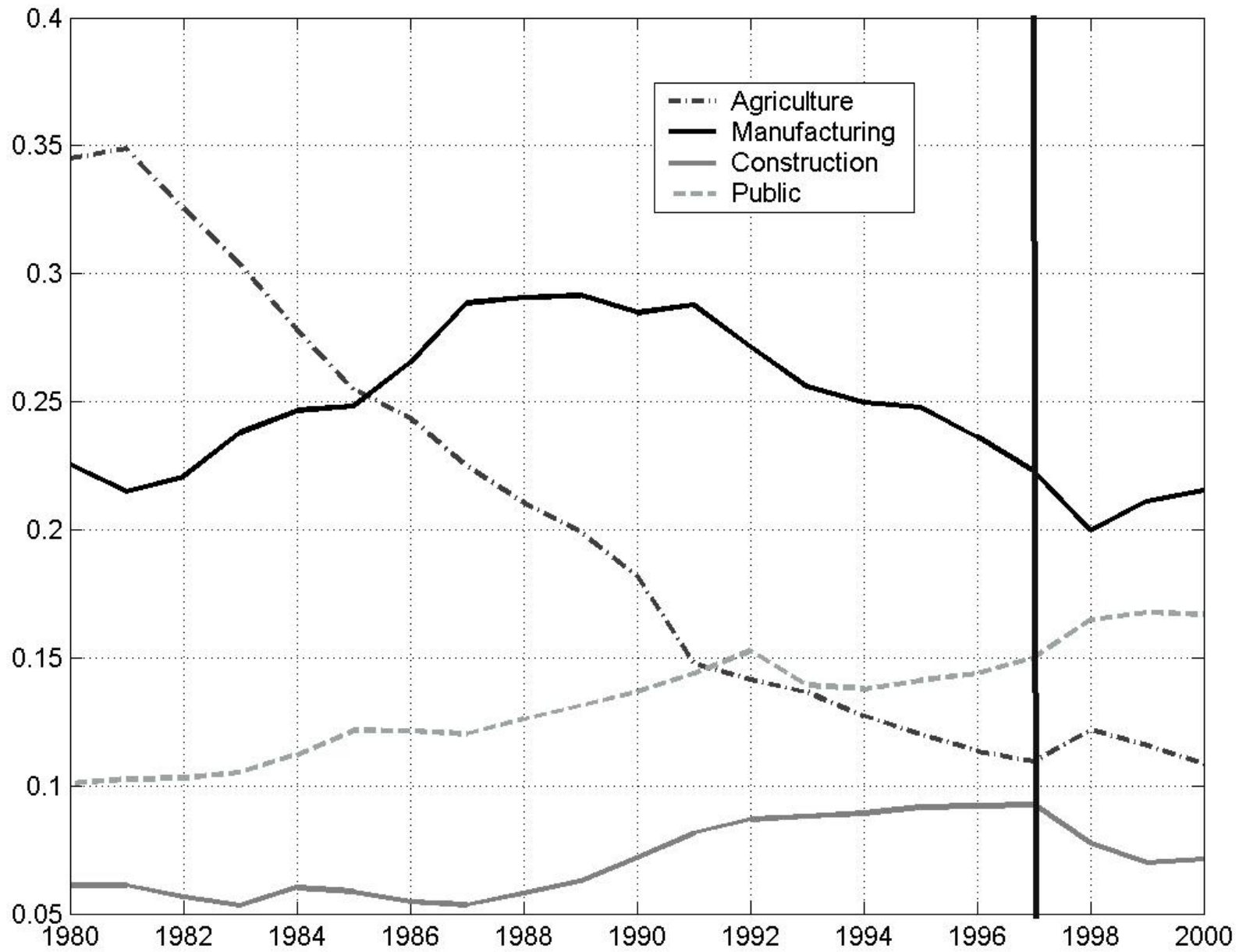


Figure 4: Sector Specific TFP: Key Sectors

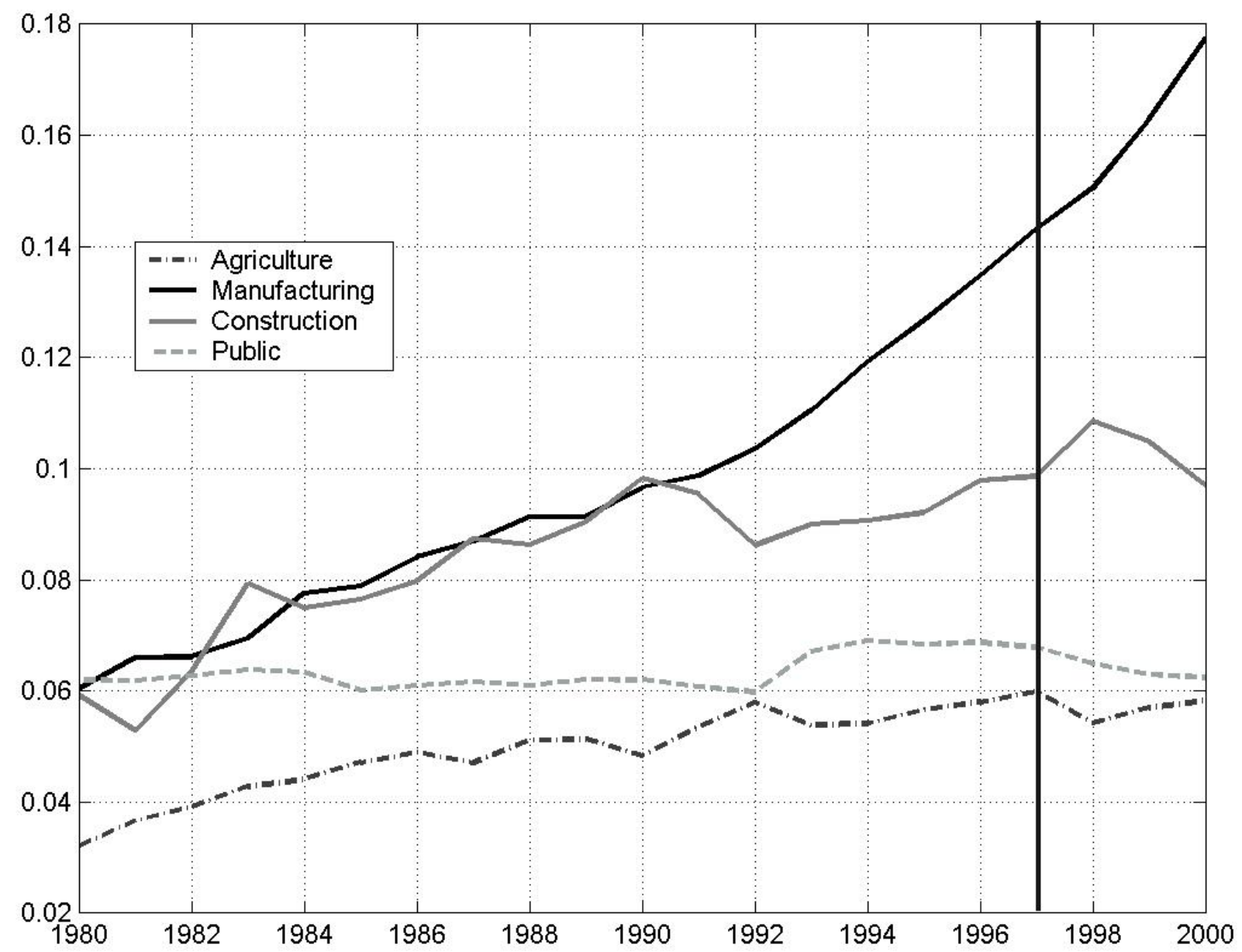


Figure 5: Decomposing TFP through Counterfactuals, Levels

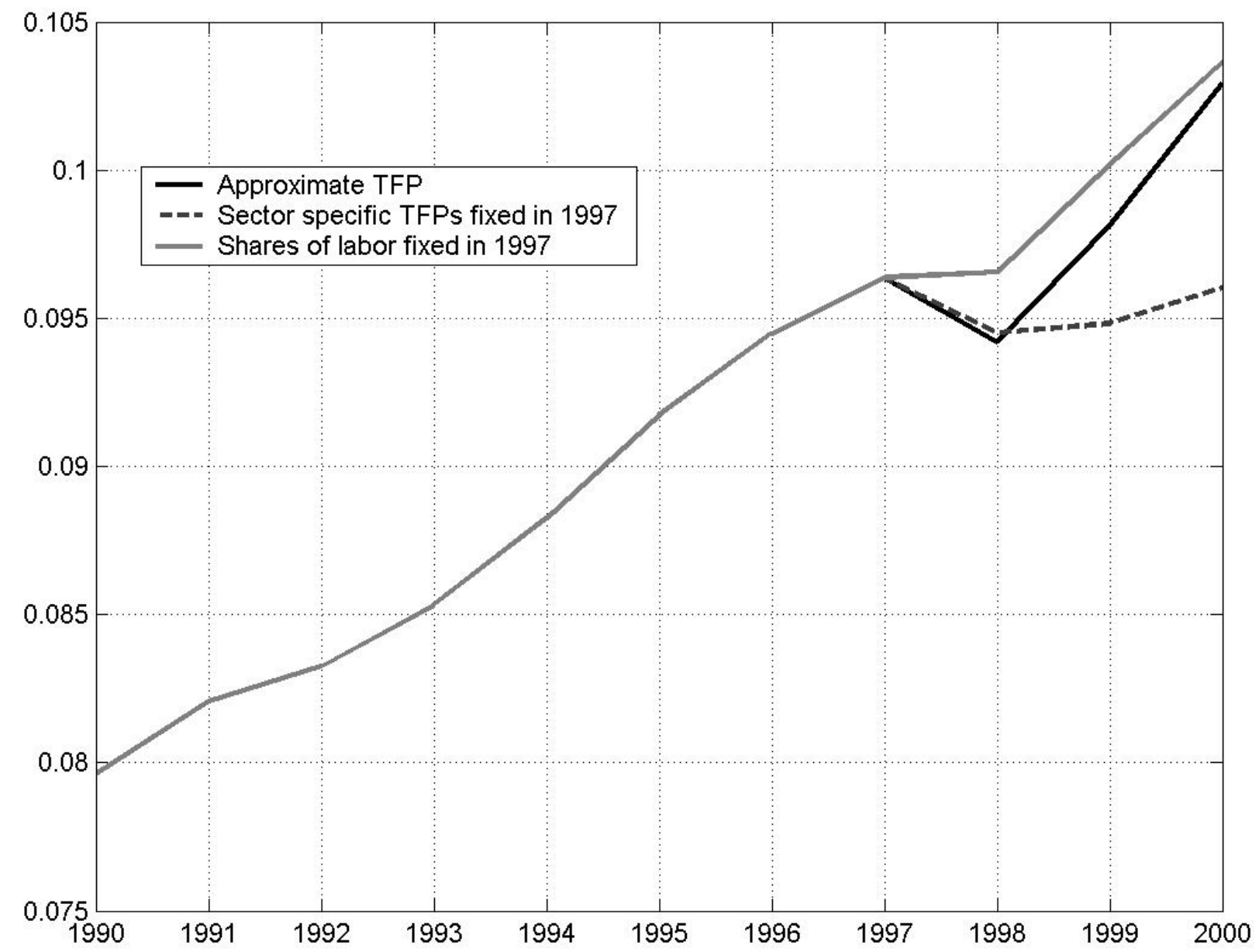


Figure 6: Decomposing TFP, With Trends

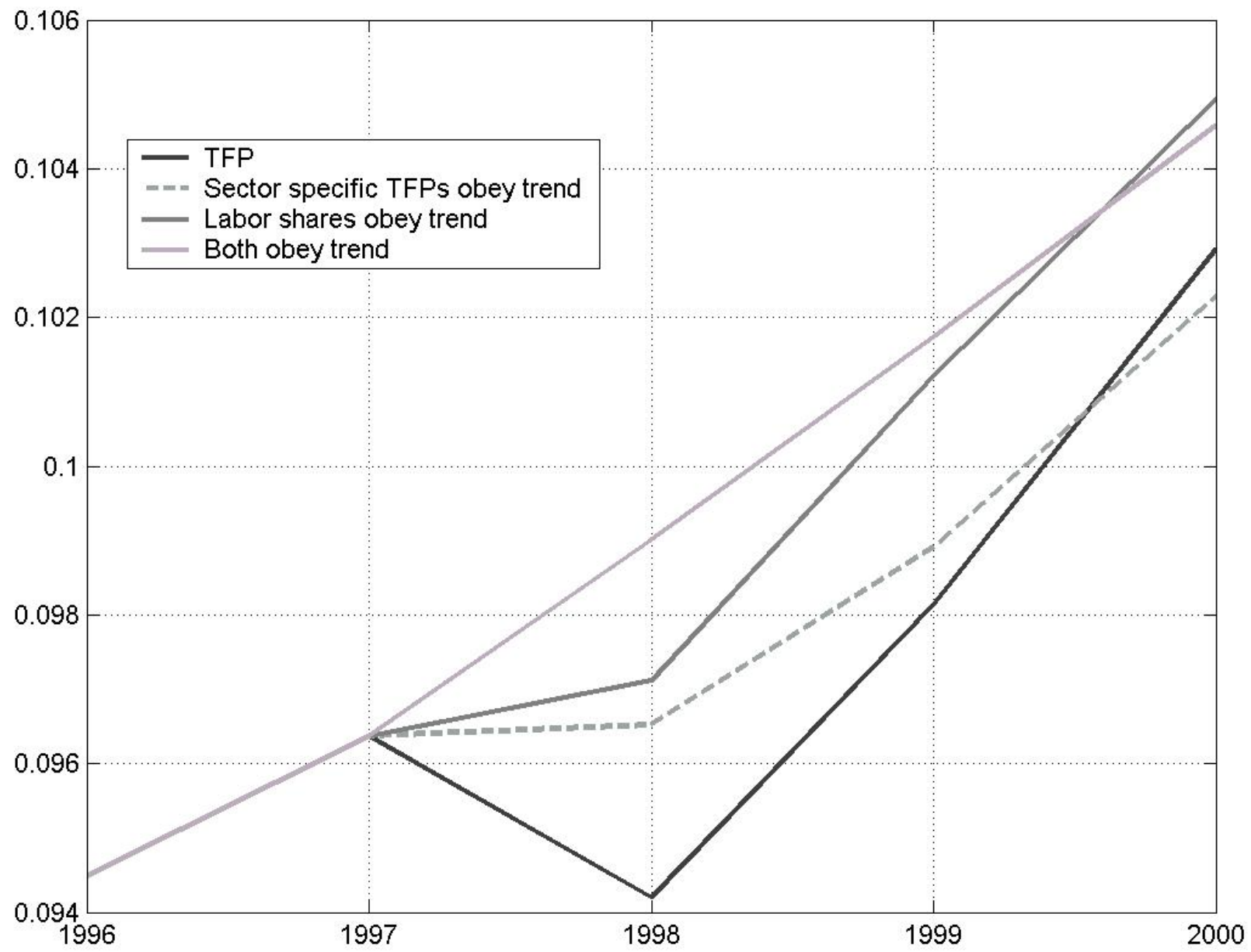


Figure 7. Decomposing TFP: One Labor Share Movement at a Time

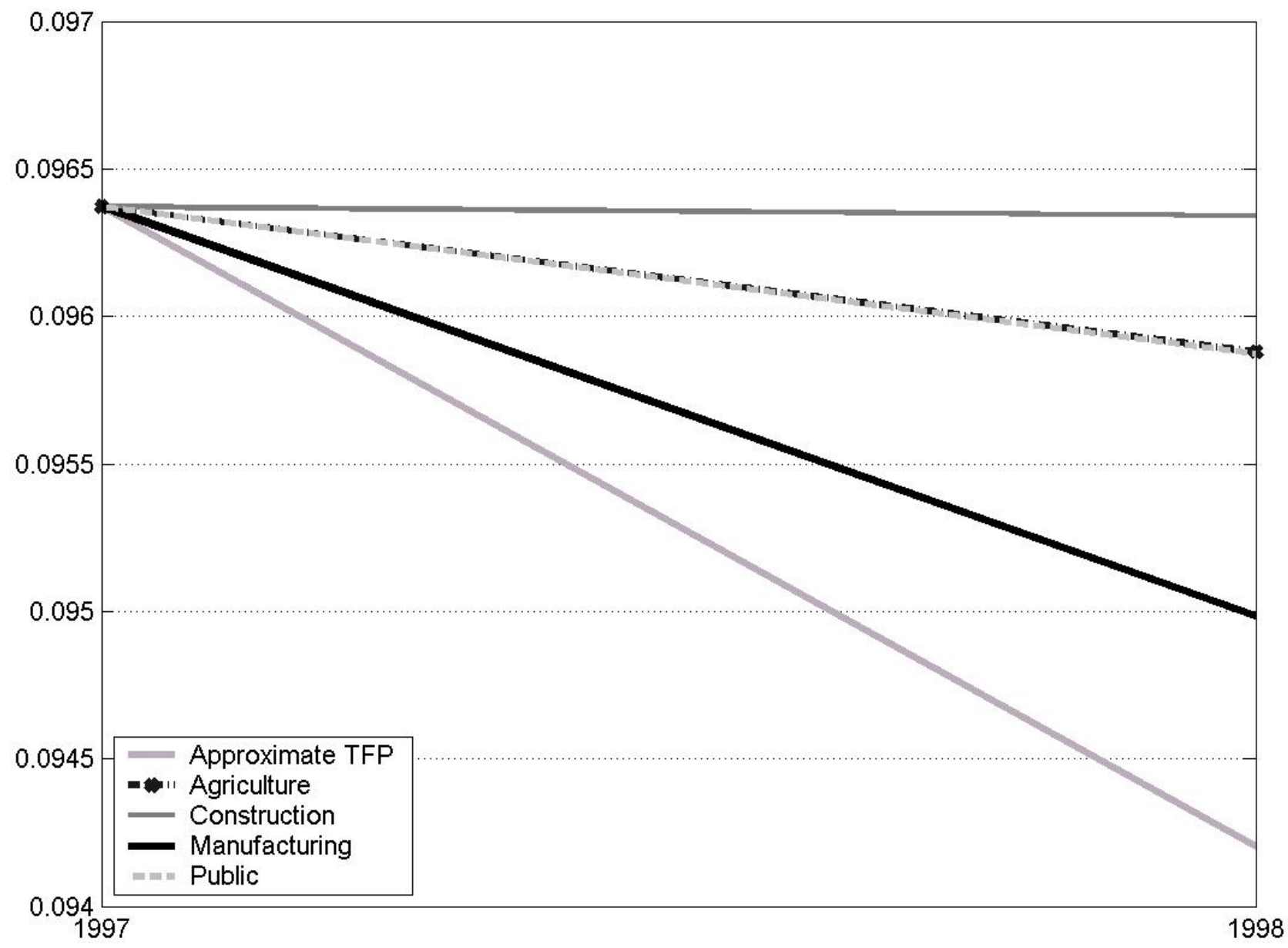


Figure 8: Sudden Stop
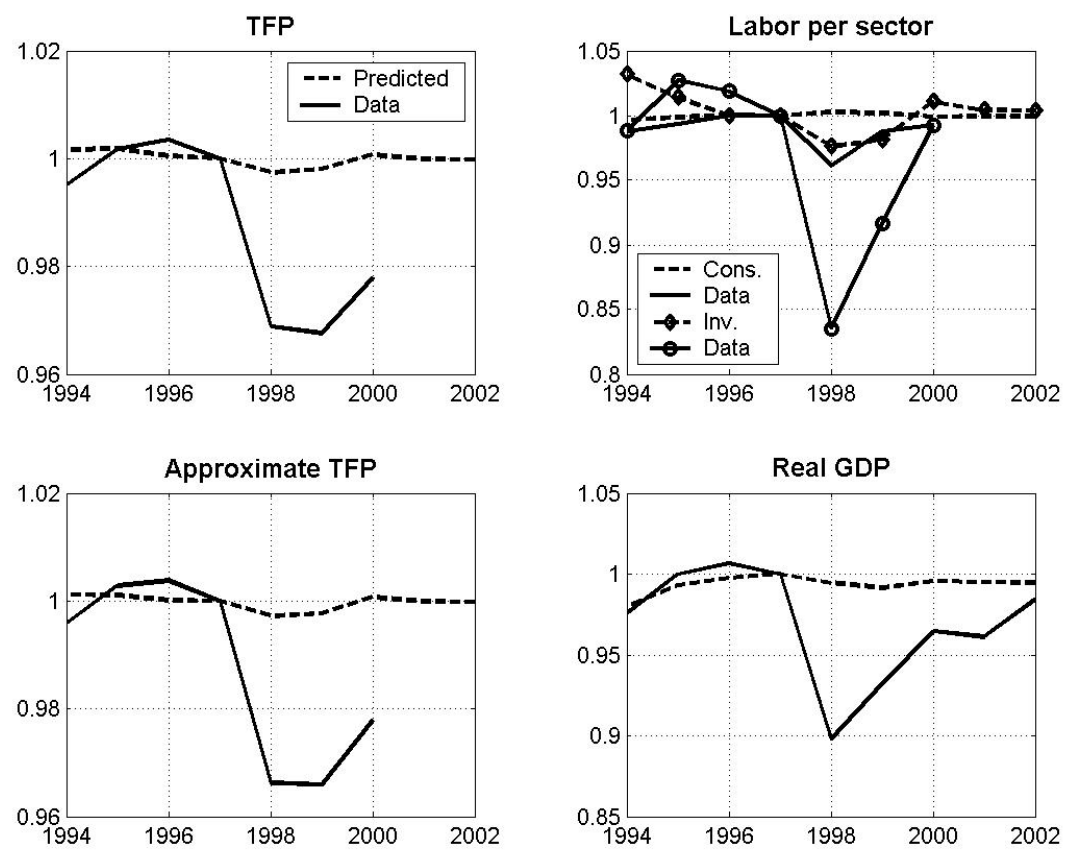

Figure 9: Sudden Stop, cont.
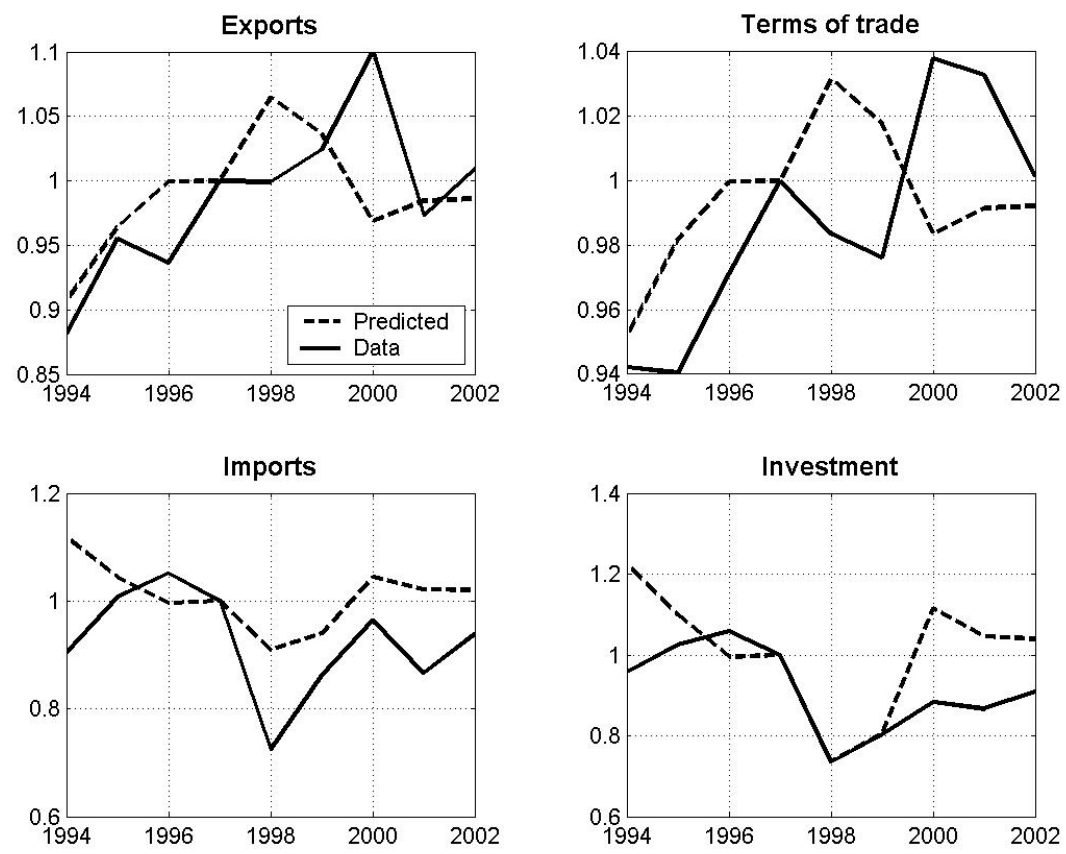
Figure 10: Sudden Stop plus Shock to Export Demand
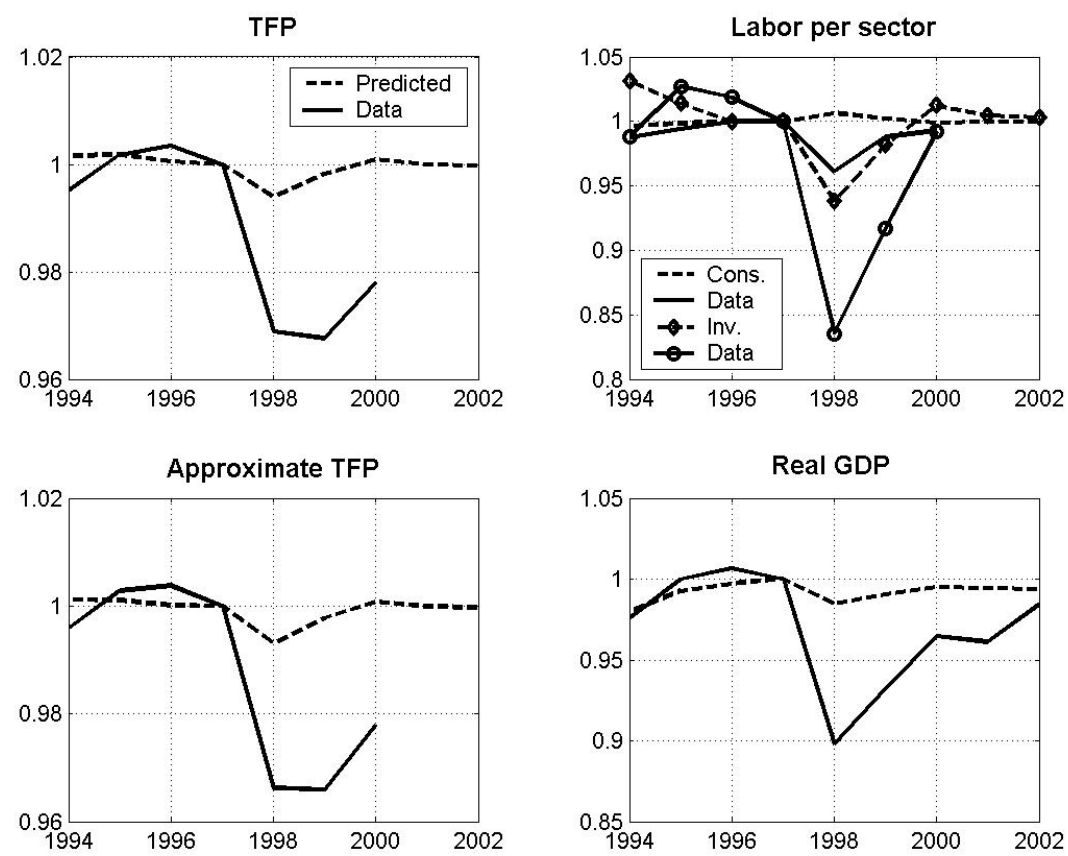

Figure 11: Sudden Stop plus Shock to Export Demand, cont.
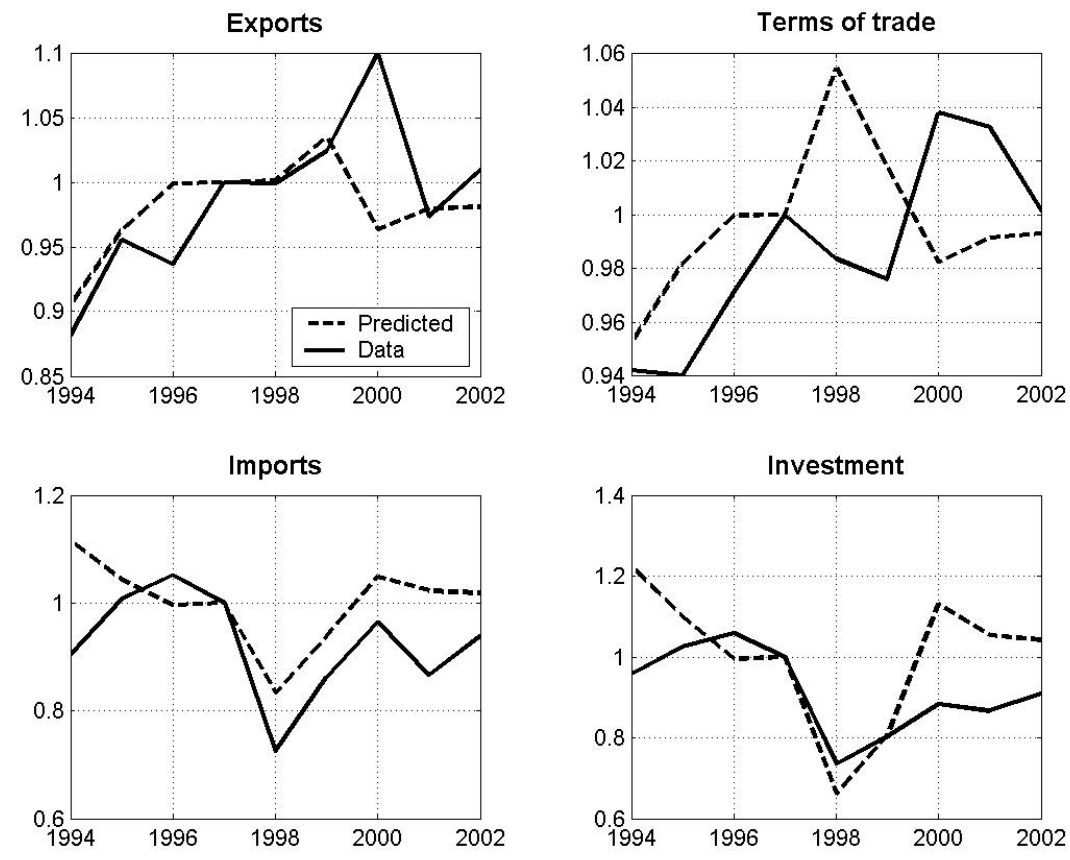
Figure 12: Sudden Stop plus Working Capital Requirements
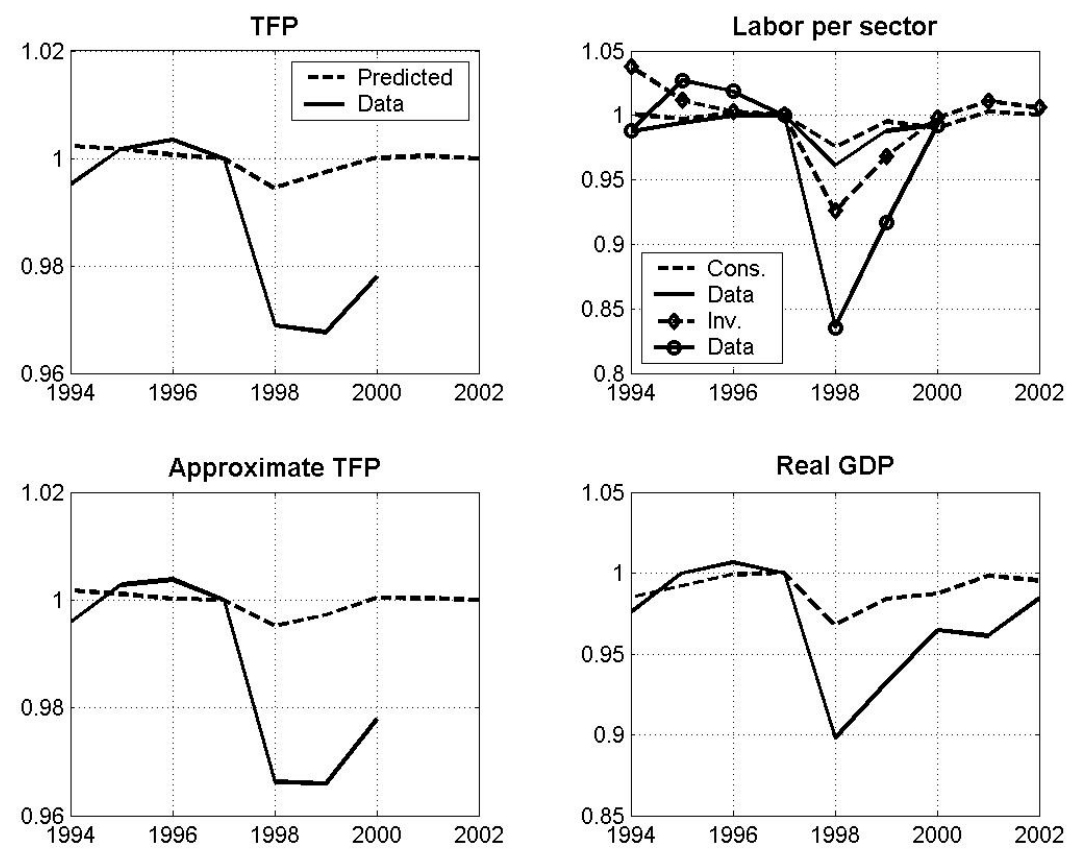

Figure 13: Sudden Stop plus Working Capital Requirements, cont.
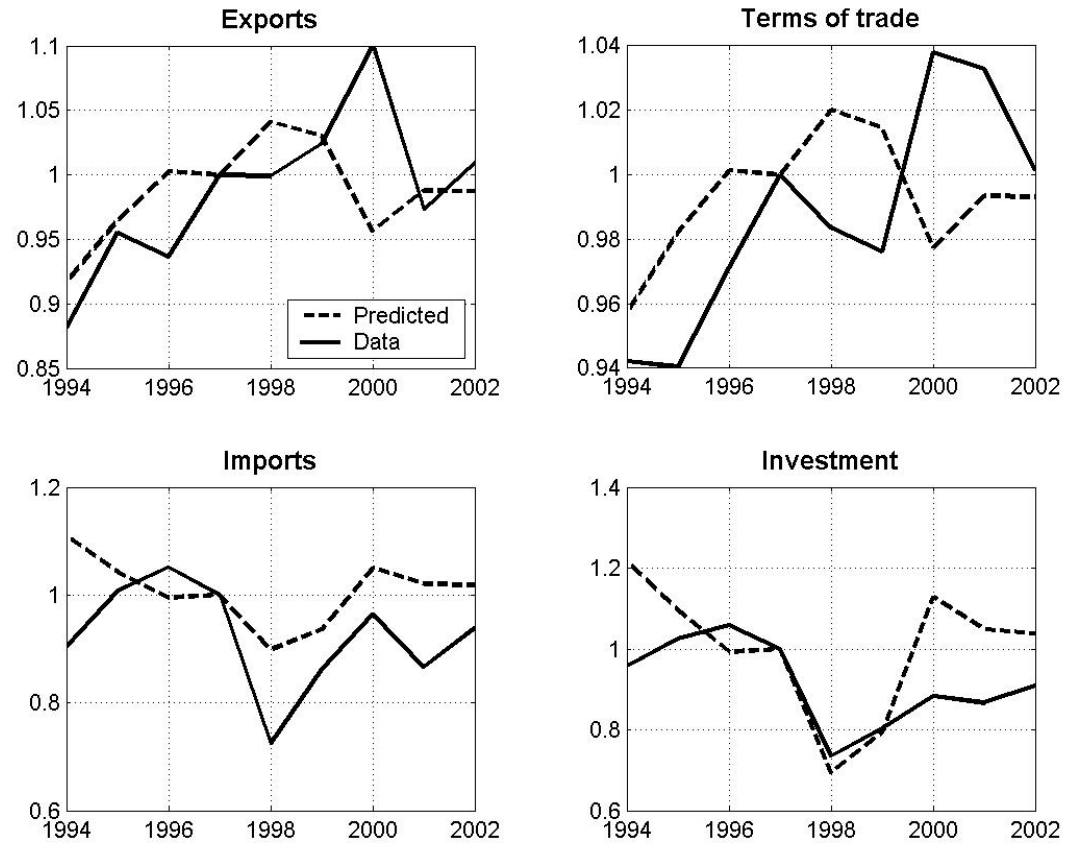
Figure 14: Sudden Stop plus Shock to Export Demand and Working Capital Requirements
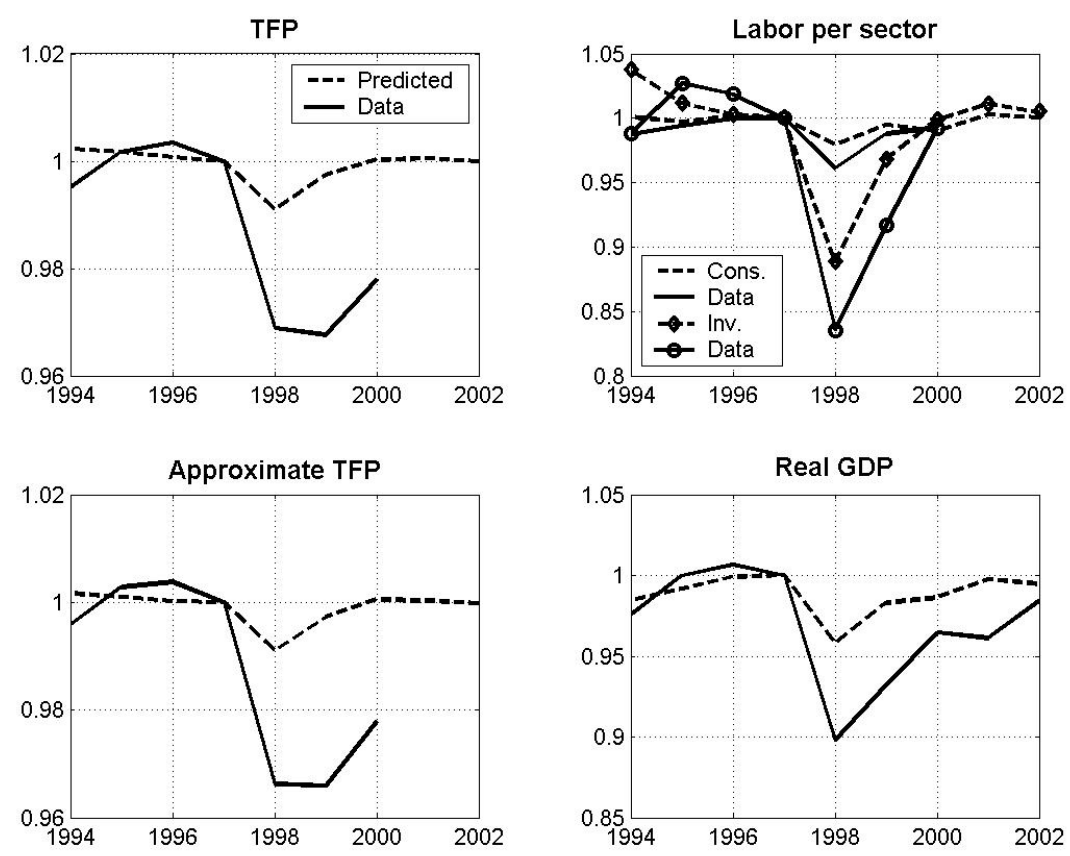

Figure 15: Sudden Stop plus Export Demand and Working Capital, cont.
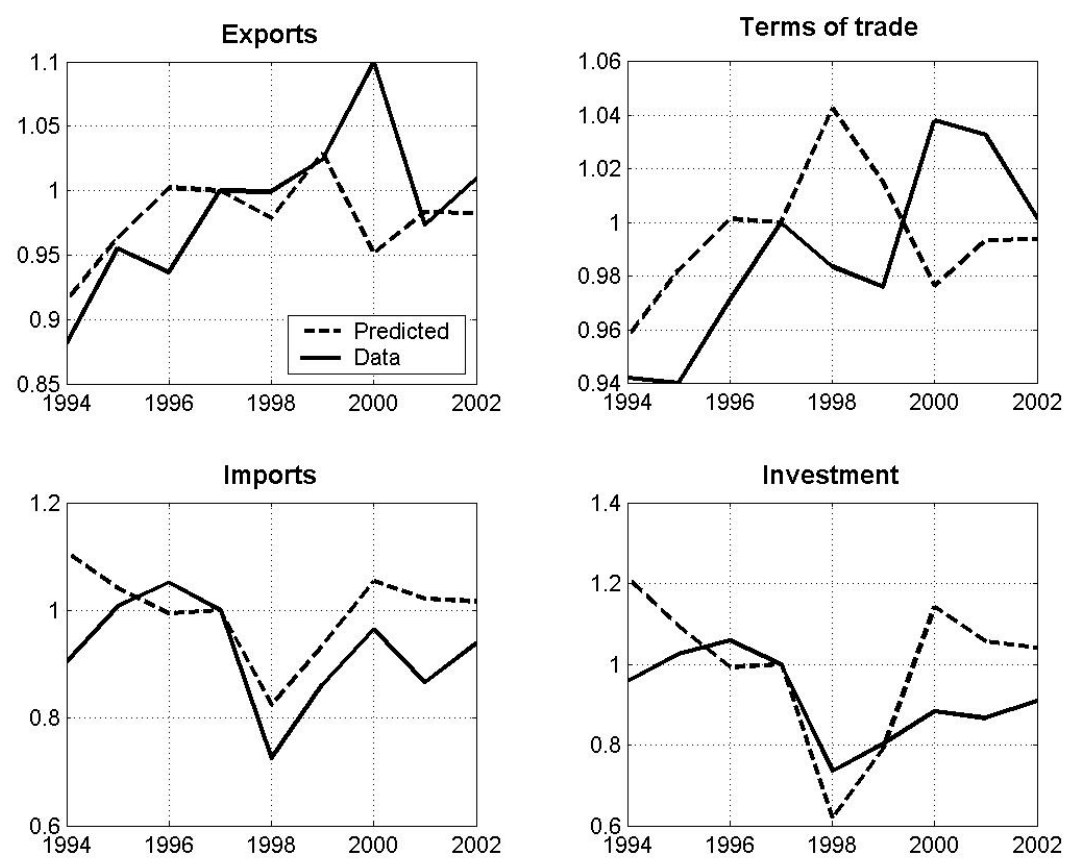